\title{
A Three-Phase Modular Isolated Matrix Converter
}

\author{
Usman Nasir, Student Member, IEEE, Alessandro Costabeber, Member, IEEE, Patrick Wheeler, Senior \\ Member, IEEE, Marco Rivera, Member, IEEE, and Jon Clare, Senior Member, IEEE
}

\begin{abstract}
This paper discusses the analysis, design and experimental validation of a Modular Isolated Matrix Converter (MIMC), including modulation, commutation and control. The MIMC topology is a single-stage high power density AC/AC converter which is attractive for traction applications and spacerestricted $L V$ or MV future distribution networks. The topology under study utilises bi-directional switches based dual-activebridge cells as basic building blocks. A single-cell would have limited practical application as the output frequency is locked to the input one. On the contrary, the repetition of single cells proposed in the MIMC extending the matrix converter concept, achieves variable frequency operation while also providing a modular structure. However, the presence of Medium Frequency (MF) transformers in each cell poses additional challenges for modulation and safe-commutation that are discussed and solved in the paper. Experimental results from a proof-of-concept $6 \mathrm{~kW}$ laboratory scale prototype validate the practical feasibility and the operation of the MIMC.
\end{abstract}

Index Terms-Direct AC/AC converters, Isolated Matrix Converter, Solid-State Transformers, Venturini Modulation, Commutation, Bi-directional switches.

\section{INTRODUCTION}

$\mathbf{I}$ $\mathrm{N}$ 1988, Alesina and Venturini proposed the first direct AC/AC power converter [1], known as Matrix Converter (MC). In a traditional MC, the output is directly connected to the input side via nine bi-directional switches, avoiding large DC link capacitors and consequently providing a single stage solution with high power density [2] and reliability [3]. The resulting topology is particularly suitable for applications such as integrated motor drives [4].

If the direct $\mathrm{AC} / \mathrm{AC}$ conversion is intended for traction or interconnection of $\mathrm{LV}$ or MV AC grids, an isolation stage must always be included to prevent fault propagation [5]. Isolation could be provided by adding line frequency transformers to the traditional MC [6] at the cost of increased volume and weight [7]. In city centres [8] or transportation systems, e.g. locomotives [9], [10], space is restricted and expensive and therefore more compact solutions based on Medium Frequency (MF) transformers are desirable [11].

Despite a large variety of ratings, applications and topologies, converters that embed an isolation stage to replace line frequency transformers are usually referred to as Solid State Transformers (SSTs) [12]. The concept was first introduced by Mc Murray in 1968 [13], however it is only now that new SSTs are being explored and employed in various applications.

U. Nasir, A. Costabeber, P. Wheeler, and J. Clare are with the Power Electronics and Machine Control Research Group, University of Nottingham, Nottingham NG7 2RD, U.K. (e-mail: usman.nasir@nottingham.ac.uk; alessandro.costabeber@nottingham.ac.uk; pat.wheeler@nottingham.ac.uk; jon.clare@nottingham.ac.uk).

M. Rivera is with the Department of Electrical Engineering, Universidad de Talca, Curicó 3341717, Chile (e-mail: marcoriv@utalca.cl).
Recently, significant work has been reported in literature, mainly for grid inter-connection [7], [14]-[17] and traction applications [7], [10], [18], [19]. MC based single-stage AC/AC SSTs are the focus of part of the latest research [20][24] due to their higher reliability and power density.

However, SST technology is still a developing field, where a broad agreement on the expected requirements and functionalities has not been reached yet. In fact, their smaller footprint compared to line frequency transformers is accompanied by higher complexity and cost as well as lower efficiency and reliability [15]. Therefore, SSTs can find their application in systems where they are not expected to simply replace low frequency transformers but where their capabilities and advantages can be better exploited, such as in future distribution networks [25] and new transportation systems [10]. It must also be noted that SSTs without energy storage, such as the MC based ones, suffer from reduced controllability under unbalanced grid conditions, due to the absence of decoupling elements. However, the advantages in terms of power density are believed to counterbalance these limitations in specific application scenarios. An example of such an application is the 400V LV mid-feeder compensator in [26] where achieving an isolated-compact converter design and voltage regulation are the key requirements while the limited ability to operate under heavy imbalance or faults is not a critical requirement. In fact, the converter can provide regulation services during normal grid operation but it will not be expected to respond to abnormal conditions that will be managed by the protection systems.

Out of the modern single-stage SSTs presented in [21], [23], [24], the topology in [23] has gained particular attention due to its reduced switch count [17]. However, the single-stage SSTs in [21], [23], [24] lack modularity in their structure, making scalability to higher power levels more challenging [20]. Recently, a single-stage modular topology has also been presented [27] whose main limitations are volume and weight since the proposed isolation stage is at low frequency.

Since isolation, modularity and flexibility are the key requirements of future electrical networks [5], a new singlestage Modular Isolated Matrix Converter (MIMC) topology was proposed in [28]. As shown in Fig. 1, the MIMC utilizes the repetition of cells made of two $\mathrm{H}$-bridges with bidirectional switches and a MF transformer to keep modularity intact. The individual cells in the proposed topology correspond to the single-phase to single-phase AC/AC topology discussed in [29]-[32]. The single cell has restricted applications as the output frequency must always match the input one [7]. To be able to achieve output frequency adaptation, in the MIMC each output phase is made by the combination of three independent single-phase to single-phase AC/AC SSTs with a 


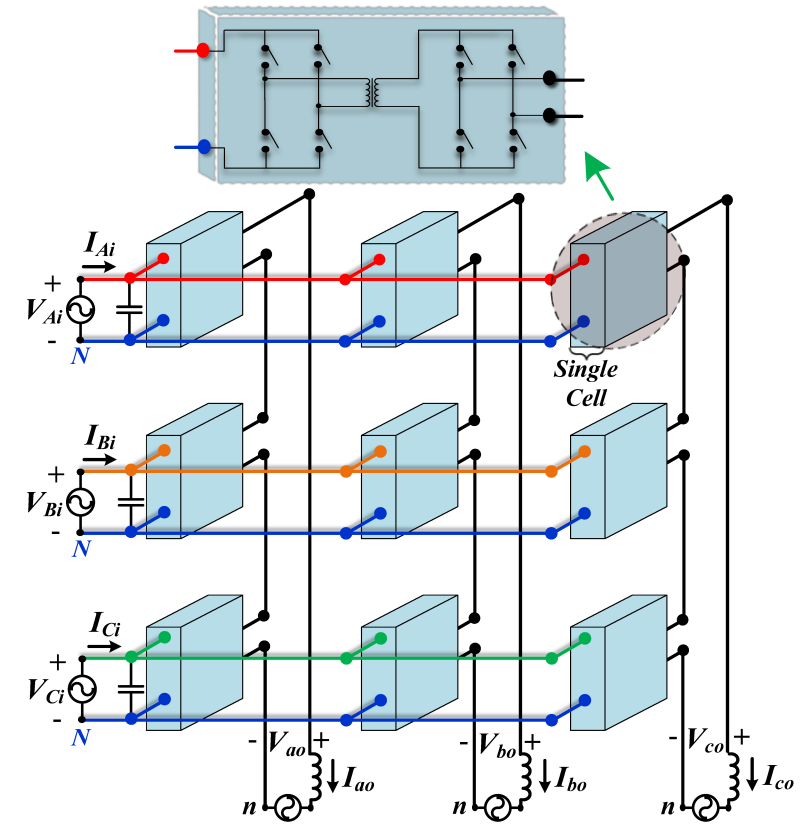

Fig. 1. Modular Isolated AC/AC Matrix Converter - three-phase to threephase

series connection at the secondary side, as shown in Fig. 2.

In the converter arrangement, the output voltage waveform demanded by each output phase can be generated by selecting the most appropriate combination of the available input voltages. As a result, the modulation techniques developed for MC are also applicable to the MIMC. As a result, the behaviour of the MIMC at the input and output terminals is the same as the one of an equivalent MC, i.e. it exhibits same characteristics and performance as $\mathrm{MC}$, with the advantage of providing embedded and distributed MF isolation and modularity. Additionally, in the MIMC the semiconductor stresses will be shared between the increased number of devices.

As discussed above, the topology has already been proposed in [28]. However, only the principle of operation and a preliminary set of simulations were discussed. The aim of this paper is to demonstrate the practical viability of the MIMC topology, providing a detailed discussion about modulation and commutation - the latter is particularly challenging because of leakage inductances, as discussed later - and providing experimental results from a laboratory-scale prototype. Considering that the three output phases are independent, the analysis and the experimental validation will refer to one of the three-phase to single-phase sections of the MIMC shown in Fig. 2. Note that the structure presented in Fig. 1 can be extended to higher voltage and power. This extension can be done by determining the number of cells $N$ based on the required voltage level and then a cascade connection of $N$ cells can be inserted into the structure of Fig. 1 to share in the input voltage $V_{K i}$.

The rest of the paper is organized as follows. The modulation and commutation methods are presented in Section II and III, respectively. The simulation and experimental validation of the proposed system are discussed in Section IV and V, respectively. Finally, the conclusions of study are presented in
Section VI.

\section{Modulation Technique}

In order to use MC modulation techniques, such as $50 \%$ Venturini Modulation, with the MIMC the first step is the identification of the Modulation States (MS) available in the topology. Considering the H-bridges in Fig. 2, with a voltage source at the input, a current source at the output and an ideal MF transformer, the generic MS matrices of the H-bridges can be defined as (1), where ' $i$ ' indicates the input side, ' $O$ ' the output side and ' $K$ ' the three input phases $K=A, B, C$.

Subsequently, to respect the constraints that the input voltage sources cannot be short circuited and that the output current source cannot be open circuited during operation [33], the three MS matrices available for modulation can be written as in (2). $M S_{1}$ and $M S_{2}$ are the two active states whereas $M S_{0}$ is a zero state matrix. Note that the zero state can be implemented with two different MS matrices that however have the same effect on the modulation waveforms.

$$
\begin{gathered}
M S_{K i}=\left[\begin{array}{ll}
S_{W K i} & S_{Y K i} \\
S_{Z K i} & S_{X K i}
\end{array}\right], \\
M S_{K o}=\left[\begin{array}{ll}
S_{W K o} & S_{Y K o} \\
S_{Z K o} & S_{X K o}
\end{array}\right] \\
M S_{1}=\left[\begin{array}{ll}
1 & 0 \\
0 & 1
\end{array}\right], M S_{2}=\left[\begin{array}{ll}
0 & 1 \\
1 & 0
\end{array}\right], \\
M S_{0}=\left[\begin{array}{ll}
0 & 0 \\
1 & 1
\end{array}\right] \text { or }\left[\begin{array}{ll}
1 & 1 \\
0 & 0
\end{array}\right]
\end{gathered}
$$

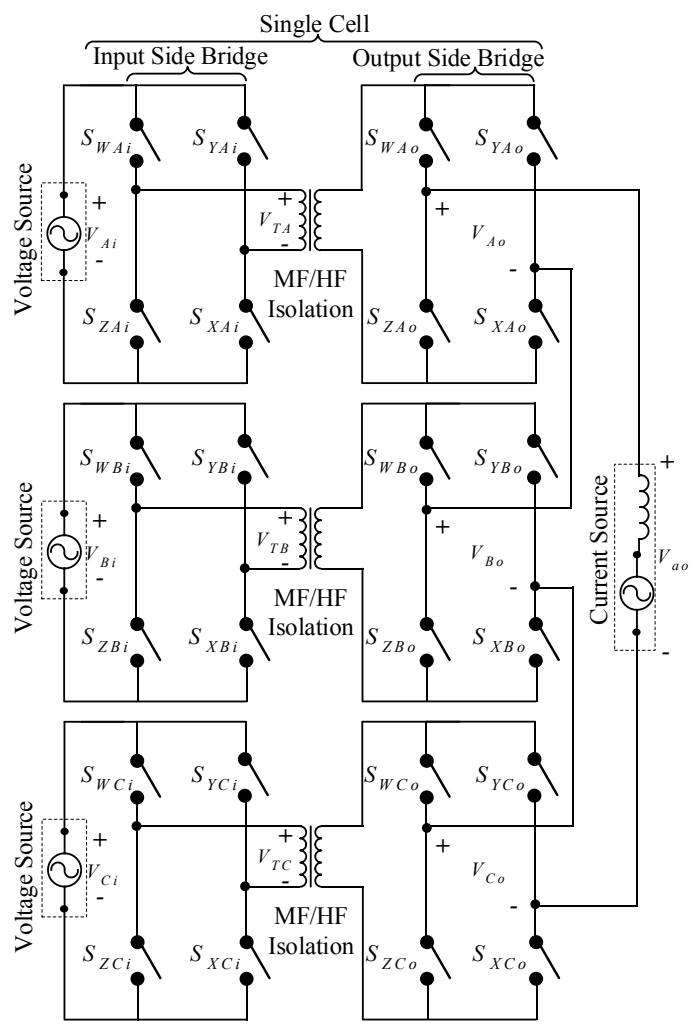

Fig. 2. Three-phase to single-phase section of the MIMC 
The basic operation of the MIMC is achieved first converting the low frequency input voltage waveform into a $50 \%$ duty cycle MF voltage waveform as shown in Fig. 3(b), by simply flipping the input voltages at the switching frequency $f_{s w}$. This is equivalent to implementing the switching function (3) on the three input side bridges. Where $T_{S}$ is the switching period, and the equation is written for brevity only for the first period $0<t<T_{S}$. The same compact notation will be adopted also for in the other equations. From (3), it can be observed that the state $M S_{1}$ will be applied for the first half of the switching period i.e. from 0 to $0.5 T_{S}$ making $V_{T K}=V_{K i}$ whereas state $M S_{2}$ for the other half of the switching period i.e. from $0.5 T_{S}$ to $T_{S}$ making $V_{T K}=-V_{K i}$ and therefore all the input side bridges are generating a $50 \%$ duty cycle MF waveform at their transformer terminals.

\begin{tabular}{c|c|c}
$V_{T K}$ & $M S_{K i}$ & Condition \\
\hline$V_{K i}$ & $M S_{1}$ & $0 \leq t \leq 0.5 T_{S}$ \\
\hline$-V_{K i}$ & $M S_{2}$ & $0.5 T_{S}<t \leq T_{S}$
\end{tabular}

A $50 \%$ duty cycle waveform at the transformer has been selected as it minimizes the transformer flux variation. It can be noted from (3) that all the three input bridges are commutated synchronously. In general, this is not a strict requirement and different phases could be flipped in different time instants without affecting the average components of the modulated waveforms. On the other hand, the harmonic content of the waveforms would be affected. These aspects are not further discussed in this paper to keep the focus on the basic modulation strategy and to simplify the graphical representation of the switching waveforms.

The $50 \%$ duty cycle modulation of the input side bridges is only meant to provide a suitable voltage waveform to the MF transformers, regardless the value of the modulation wave. Instead, the output bridge voltages $V_{K o}$ in Fig. 2 are defined by the $50 \%$ Venturini Modulation according to (4), where $D_{k j}$ is the duty cycle of the input phase $K$ in the generation of the output voltage $j$. It can be observed from (4)-(6) that the equations are the same as the ones used in standard MCs, where the time during which each of the input phases contributes to the output voltage is defined by the Venturini Modulation.

$$
\begin{aligned}
D_{K j} & =\frac{1}{3}\left(1+\frac{2 V_{K i} V_{j o}}{V_{m}^{2}}\right) \\
V_{K i} & =V_{m} \sin \left(\omega_{i} t+\phi_{K}\right) \\
V_{j o} & =q V_{m} \sin \left(\omega_{o} t+\phi_{j}\right)
\end{aligned}
$$

Where $V_{K i}, K=A, B, C$ and $V_{j o}, j=a, b, c$ are the three-phase input and output voltages, respectively. For the simplified three-phase to single-phase system under study, only $j=a$ is considered. The duty cycle arrangement in this simplified case is illustrated in Fig. 4. The duty cycle arrangement of Fig. 4 can be attained by implementing the switching functions (7)-(9) in each of the output side bridges of the MIMC. The switching function (7) will be applied to the output bridge of the top cell. In (7), the duty cycle $D_{A a}$ can be less than or equal to 0.5 i.e. $D_{A a} T_{S} \leq 0.5 T_{S}$ or greater

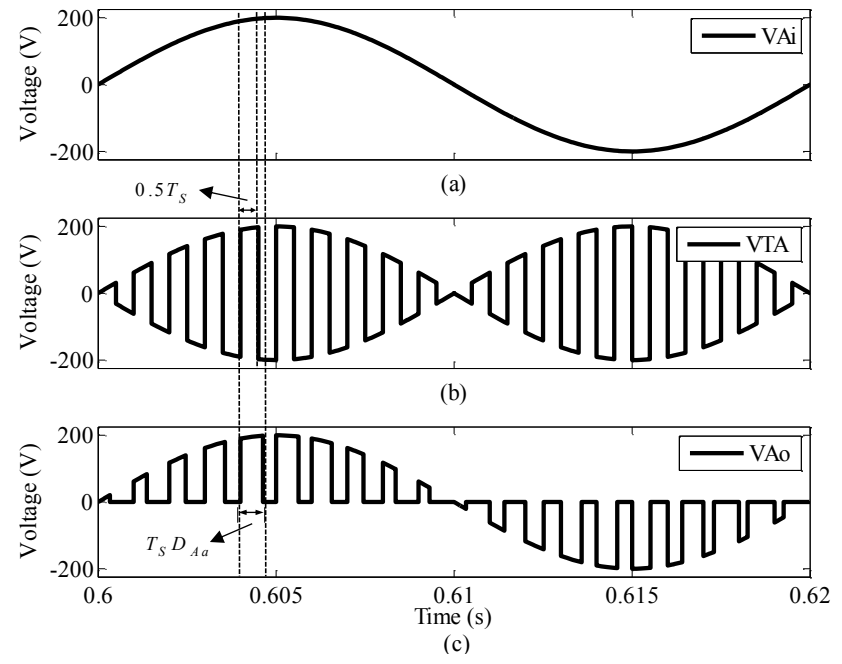

Fig. 3. Theoretical voltage waveforms in a single-cell as a result of $50 \%$ Venturini Modulation: (a) Input voltage $V_{A i}$. (b) Transformer voltage $V_{T A}$. (c) Output voltage $V_{A o}$.

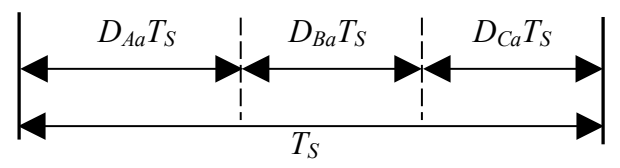

Fig. 4. Arrangement of the duty cycles in a three-phase to single-phase MC

than 0.5 i.e. $D_{A a} T_{S}>0.5 T_{S}$. In case the duty cycle $D_{A a}$ is below or equal to 0.5 , the condition $D_{A a} T_{S} \leq 0.5 T_{S}$ becomes valid and two intervals are possible in (7) based on which the two steady-states i.e. $M S_{1}$ and $M S_{0}$ will be applied. In short, if the condition $D_{A a} T_{S} \leq 0.5 T_{S}$ is satisfied, then the active state $M S_{1}$ will be applied for a duration or interval of $0 \leq t \leq D_{A a} T_{S}$ and state $M S_{0}$ will be applied for the remaining interval $D_{A a} T_{S}<t \leq T_{S}$. Similarly, the switching

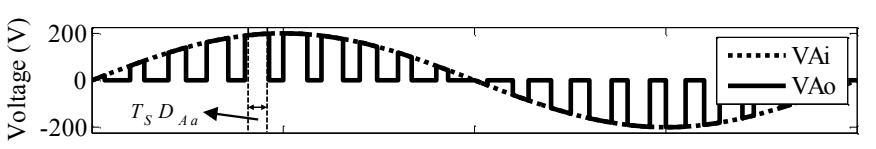

(a)

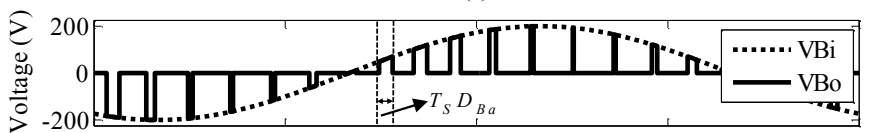

(b)

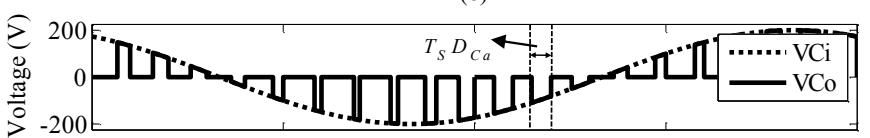

(c)

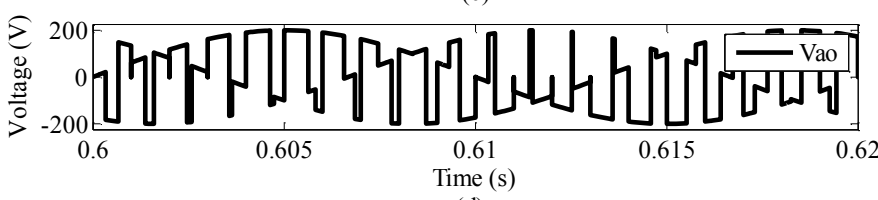

(d)

Fig. 5. Theoretical voltage waveforms in the three-phase to single-phase MIMC as a result of $50 \%$ Venturini Modulation. (a)-(c) Input and output voltages of the cells $V_{K i}$ and $V_{K o}$. (d) Total output voltage $V_{a o}$ of (10). 
function (8) will be applied to output bridge of middle cell. For instance if the first condition i.e. $D_{A a} T_{S} \leq 0.5 T_{S} \leq$ $\left(D_{A a}+D_{B a}\right) T_{S}$ is true in (8) then there are a total of 4 intervals in which the state $M S_{0}$ will be applied for the interval $0 \leq t \leq D_{A a} T_{S}, M S_{1}$ for interval $D_{A a} T_{S}<t \leq 0.5 T_{S}$, $M S_{2}$ for interval $0.5 T_{S}<t \leq\left(D_{A a}+D_{B a}\right) T_{S}$ and again $M S_{0}$ for the remaining interval $\left(D_{A a}+D_{B a}\right) T_{S}<t \leq T_{S}$. The other conditions and interval of all the switching functions in (7)-(9) can be interpreted following the discussed approach.

It is important to note that (7)-(9) are written under the assumption that all the input bridges are flipped synchronously, and therefore the voltage applied to each of the MF transformer primaries $V_{T K}$ and modulated by the output bridges equals the corresponding phase voltage $V_{K i}$ for the first half of the switching period and $-V_{K i}$ for the other half.

Fig. 3 shows the basic waveforms for the top cell in Fig. 2 as a result of the switching functions given in (3) and (7)(9). The cell output voltages $V_{K o}$ as a result of the switching functions are presented in Fig. 5. It is important to note, from Fig. 5, that the total output voltage $V_{a o}$ is the sum of the individual output voltages of the cells. This is because of the series connection of the output side bridges in the three-phase to single-phase system of Fig. 2, the cell voltages $V_{K o}(7)-(9)$, depicted in Fig. 5, are summed as shown in (10) to generate the total output voltage $V_{a o}$. The instantaneous output voltage $V_{a o}$ can also be rewritten as (11) which means that the input voltage $V_{A i}$ will appear at the output i.e. $V_{a o}=V_{A i}$ for a duration of $0 \leq t \leq D_{A a} T_{S} V_{A i}$ and so on thus follows the arrangement of MCs shown in Fig. 4.

\begin{tabular}{c|c|c|c}
$V_{A o}$ & $M S_{A o}$ & Interval & Condition \\
\hline$V_{A i}$ & $M S_{1}$ & $0 \leq t \leq D_{A a} T_{S}$ & $D_{A a} T_{S} \leq 0.5 T_{S}$ \\
0 & $M S_{0}$ & $D_{A a} T_{S}<t \leq T_{S}$ & \\
\hline$V_{A i}$ & $M S_{1}$ & $0 \leq t \leq 0.5 T_{S}$ & $D_{A a} T_{S}>0.5 T_{S}$ \\
$V_{A i}$ & $M S_{2}$ & $0.5 T_{S}<t \leq D_{A a} T_{S}$ & \\
0 & $M S_{0}$ & $D_{A a} T_{S}<t \leq T_{S}$ &
\end{tabular}

\begin{tabular}{c|c|c|c}
$V_{B o}$ & $M S_{B o}$ & Interval & Condition \\
\hline 0 & $M S_{0}$ & $0 \leq t \leq D_{A a} T_{S}$ & \\
$V_{B i}$ & $M S_{1}$ & $D_{A a} T_{S}<t \leq 0.5 T_{S}$ & $D_{A a} T_{S} \leq 0.5 T_{S}$ \\
$V_{B i}$ & $M S_{2}$ & $0.5 T_{S}<t \leq\left(D_{A a}+D_{B a}\right) T_{S}$ & $\leq\left(D_{A a}+D_{B a}\right) T_{S}$ \\
0 & $M S_{0}$ & $\left(D_{A a}+D_{B a}\right) T_{S}<t \leq T_{S}$ & \\
\hline 0 & $M S_{0}$ & $0 \leq t \leq D_{A a} T_{S}$ & $0.5 T_{S} \leq D_{A a} T_{S}$ \\
$V_{B i}$ & $M S_{2}$ & $D_{A a} T_{S}<t \leq\left(D_{A a}+D_{B a}\right) T_{S}$ & \\
0 & $M S_{0}$ & $\left(D_{A a}+D_{B a}\right) T_{S}<t \leq T_{S}$ & \\
\hline 0 & $M S_{0}$ & $0 \leq t \leq D_{A a} T_{S}$ & $\left(D_{A a}+D_{B a}\right) T_{S}$ \\
$V_{B i}$ & $M S_{1}$ & $D_{A a} T_{S}<t \leq\left(D_{A a}+D_{B a}\right) T_{S}$ & $\leq 0.5 T_{S}$ \\
0 & $M S_{0}$ & $\left(D_{A a}+D_{B a}\right) T_{S}<t \leq T_{S}$ &
\end{tabular}

\begin{tabular}{c|c|c|c}
$V_{C o}$ & $M S_{C o}$ & Interval & Condition \\
\hline 0 & $M S_{0}$ & $0 \leq t \leq\left(D_{A a}+D_{B a}\right) T_{S}$ & $\left(D_{A a}+D_{B a}\right) T_{S}$ \\
$V_{C i}$ & $M S_{1}$ & $\left(D_{A a}+D_{B a}\right) T_{S}<t \leq 0.5 T_{S}$ & $\leq 0.5 T_{S}$ \\
$V_{C i}$ & $M S_{2}$ & $0.5 T_{S}<t \leq T_{S}$ & \\
\hline 0 & $M S_{0}$ & $0<t \leq\left(D_{A a}+D_{B a}\right) T_{S}$ & $\left(D_{A a}+D_{B a}\right) T_{S}$ \\
$V_{C i}$ & $M S_{2}$ & $\left(D_{A a}+D_{B a}\right) T_{S}<t \leq T_{S}$ & $>0.5 T_{S}$
\end{tabular}

$$
V_{a o}=\sum_{K=A, B, C} V_{K o}=V_{A o}+V_{B o}+V_{C o}
$$

$$
V_{a o}=\left\{\begin{array}{c|c}
\text { Voltage } & \text { Interval } \\
\hline V_{A i} & 0 \leq t \leq D_{A a} T_{S} \\
V_{B i} & D_{A a} T_{S}<t \leq\left(D_{A a}+D_{B a}\right) T_{S} \\
V_{C i} & \left(D_{A a}+D_{B a}\right) T_{S}<t \leq T_{S}
\end{array}\right\}
$$

For the practical implementation of (7)-(9), the required states in each of the cells in Fig. 2 are $M S_{K i} M S_{K o}=\left[M S_{1} M S_{1}, \quad M S_{2} M S_{2}, \quad M S_{1} M S_{0}\right.$, $\left.M S_{2} M S_{0}\right]$ and are illustrated in Fig. 6(a)-(d), respectively. The output voltage waveforms - as well as input and output currents - have harmonic content that can be derived analytically by applying the approach proposed in [34].
Considering that the output voltage spectrum of the MIMC is the same as the one of the standard MC, discussion about harmonics in this paper is limited to the transformer voltages $V_{T K}$, whose Fourier Series, shown in (12), is essential for the MF transformer design. Instead, the harmonic spectrum of the cell output voltages $V_{K o}$ given in (7)-(9), is only used for the validation of the modulation method. By neglecting 


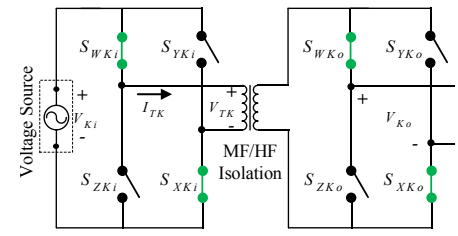

(a) Modulation state $M S_{1} M S_{1}$

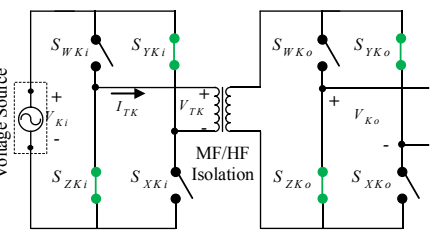

(b) Modulation state $M S_{2} M S_{2}$

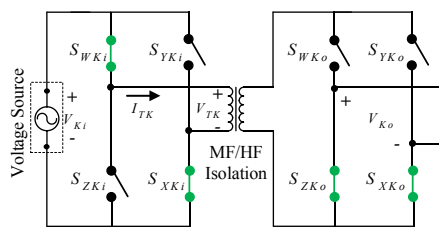

(c) Modulation state $M S_{1} M S_{0}$

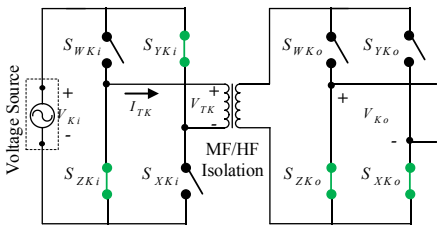

(d) Modulation state $M S_{2} M S_{0}$

Fig. 6. States required in a single-cell for the implementation of 50\% Venturini Modulation

the switching harmonics, the low frequency components of the individual cell voltages $V_{K o}$ are given in (13). Due to the series connection at the output side, these components reduce to the desired fundamental (14) as the other terms in $V_{a o}$ cancel in the sum. Equation (14) confirms that 50\% Venturini Modulation is applicable to the three-phase to single-phase MIMC. Note that the theoretical derivation of (12) and (13) is given in Appendix. The voltage regulation ratio of MIMC is dependant on the turn-ratio of the MF transformer but assuming turn-ratio of the transformer to be unity, a maximum voltage regulation ratio of 0.86 can be achieved by modifying the duty cycle (4) to inject third-harmonic.
So far, the analysis of the modulation technique for the MIMC has assumed ideal semiconductor devices, characterised by instantaneous switching. In addition, the MF transformer has been considered ideal, with zero leakage inductance. When implementing the modulation in a practical converter, the two assumptions lose validity and the modulation must be augmented by a suitable strategy to guarantee safe commutation of the bidirectional switches. Switching times can be easily taken into account by implementing a modified version of the 4-step commutation used in MC [2]. Instead, taking into account a non-zero leakage inductance of the MF transformer is a more challenging aspect, discussed in detail in the following section.

$$
\begin{gathered}
V_{T K}(t)=\frac{2 V_{m}}{\pi} \sum_{n=1,3,5, \ldots}^{\infty} \frac{1}{n}\left(\cos \left(n \omega_{s} t-\omega_{i} t-\phi_{K}\right)-\cos \left(n \omega_{s} t+\omega_{i} t+\phi_{K}\right)\right) \\
V_{K o}(t)=\frac{V_{m}}{3} \sin \left(\omega_{i} t+\phi_{K}\right)+\frac{q V_{m}}{6} \sin \left(2 \omega_{i} t-\omega_{o} t-\phi_{K}\right)-\frac{q V_{m}}{6} \sin \left(2 \omega_{i} t+\omega_{o} t-\phi_{K}\right)+\frac{q V_{m}}{3} \sin \left(\omega_{o} t\right) \\
V_{a o}(t)=\sum_{K=A, B, C} V_{K o}(t)=q V_{m} \sin \left(\omega_{o} t\right)
\end{gathered}
$$

\section{Commutation Method}

In MCs, the commutation method is designed to safely change the state of the bidirectional switches without open circuiting the output currents or short circuiting the input voltage sources.

In the MIMC, each bridge can achieve independent 4step commutation method, as presented in [29], only if the impact of the MF transformer leakage inductance is neglected. However, with non-negligible leakage inductance, the standard 4-step commutation method can cause overvoltage across the semiconductor devices when a commutation of an output bridge in one of the cells occurs. This because a commutation of the output bridge requires a sudden reversal of the current through the leakage inductance $I_{T K}$, which always flips between $+I_{a o}$ (grid current) and $-I_{a o}$ depending on the state of the output bridge.

To highlight this phenomenon, an example of the ideal commutation waveforms in a single-cell during a switching period of $T_{S}$ are shown in Fig. 7. It can be seen that the state transition from $M S_{1} M S_{1}$ to $M S_{2} M S_{2}$ is requiring the transformer current $I_{T B}$ to undergo sudden reversal from $-I_{a o}$ and $+I_{a o}$ which will generate a voltage spike in a practical transformer where leakage inductance is non-negligible. A detailed discussion about the impact of the leakage inductance

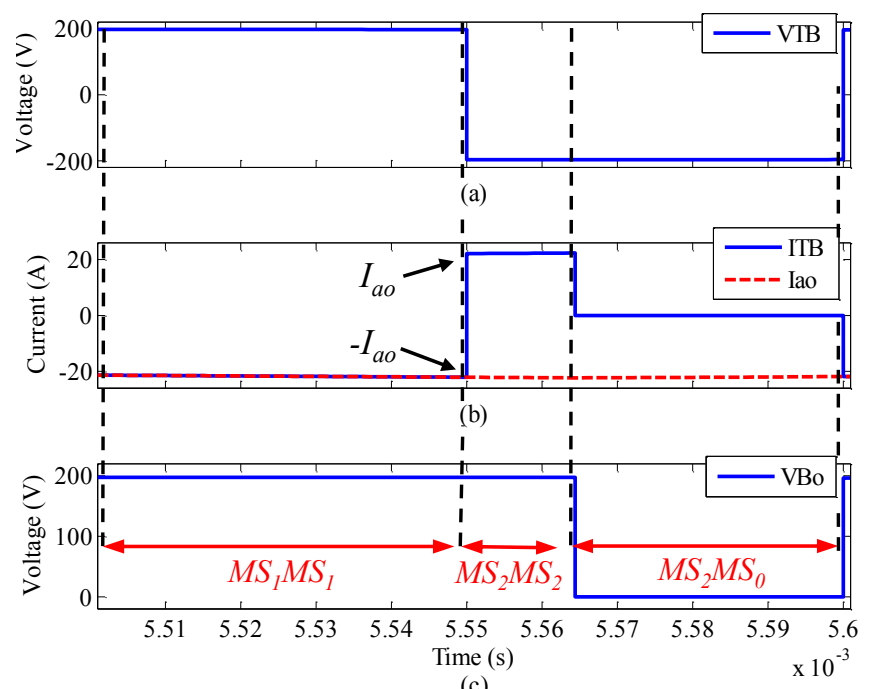

(c)

Fig. 7. Example of ideal transformer current in a single cell operated with the states required by $50 \%$ Venturini Modulation - zero leakage transformer (a) Transformer voltage $V_{T B}$ (b) Current $I_{T B}$ (c) Output voltage $V_{B o}$ 
on the commutation process can be found in [35]. The consequence is that the standard 4-step commutation can be applied to the MIMC only if all the bridges have dissipative clamps to protect them against over-voltage. This causes additional loss as the clamp circuit will be triggered every time the modulator requires a state change that corresponds to a reversal of the leakage inductance current. Reduction of leakage inductance [29] can mitigate but not eliminate the problem. To achieve safe commutation, various commutation methods have been reported in literature [36]-[39] which suggest the use of additional capacitor either in parallel [38] or in series [39] to transformer. However, these options come at the cost of reduced power density and increased power losses.

\section{A. Leakage-Tolerant Source-Based Commutation Method}

A solution to the commutation problem has been recently discussed in [35], where the analysis is focused on a single cell of the MIMC converter in Fig. 2. The paper proposed the exploitation of additional states available in the converter that would not be necessary in ideal conditions but become essential when dealing with the leakage inductance issue. In particular, [35] proposes the introduction of a "current decoupling phase", where the output bridge is temporarily put in an controlled short circuit state during which the leakage inductance current is reversed, driven by the input voltage. The converter states are selected so that the temporary output short naturally terminates when the leakage inductance current matches the value of the output current. For this reason the short is "controlled" and does not require any high bandwidth current measurement but only an appropriate fixed timing of the commutation sequence. The method guarantees safecommutation without triggering the protection clamps for most of the line period, except during the intervals where the available input voltage is not enough to drive the leakage inductance current, i.e. around the zero crossings of the input voltage.

Based on the leakage-inductance-tolerant commutation scheme discussed in [35], a Finite State Machine (FSM) has been implemented as shown in Fig. 8 to move between the steady states of Fig. 6. In the proposed FSM, the commutation paths are represented by arrows, temporary commutation states by small circles and steady states by large grey circles. In the same way as MS matrices, input and output bridge Commutation State (CS) matrices of single-cell can be represented by (15) where each bi-directional switch is composed of two IGBTs. For instance, $S_{W K i}$ contains $S_{W K 0 i}$ and $S_{W K 1 i}$ in the common-collector configuration as shown in Fig. 9. The definition of the CS matrices is reported in (16). The state change variable $S_{N}$ stores the information regarding the required next steady state. $T_{c o m m}$ controls the time delay between the commutation states and for the sake of simplicity, the delay time $T_{\text {comm }}$ was fixed for all the commutation steps. For instance, assume that the FSM is in commutation state $B B$

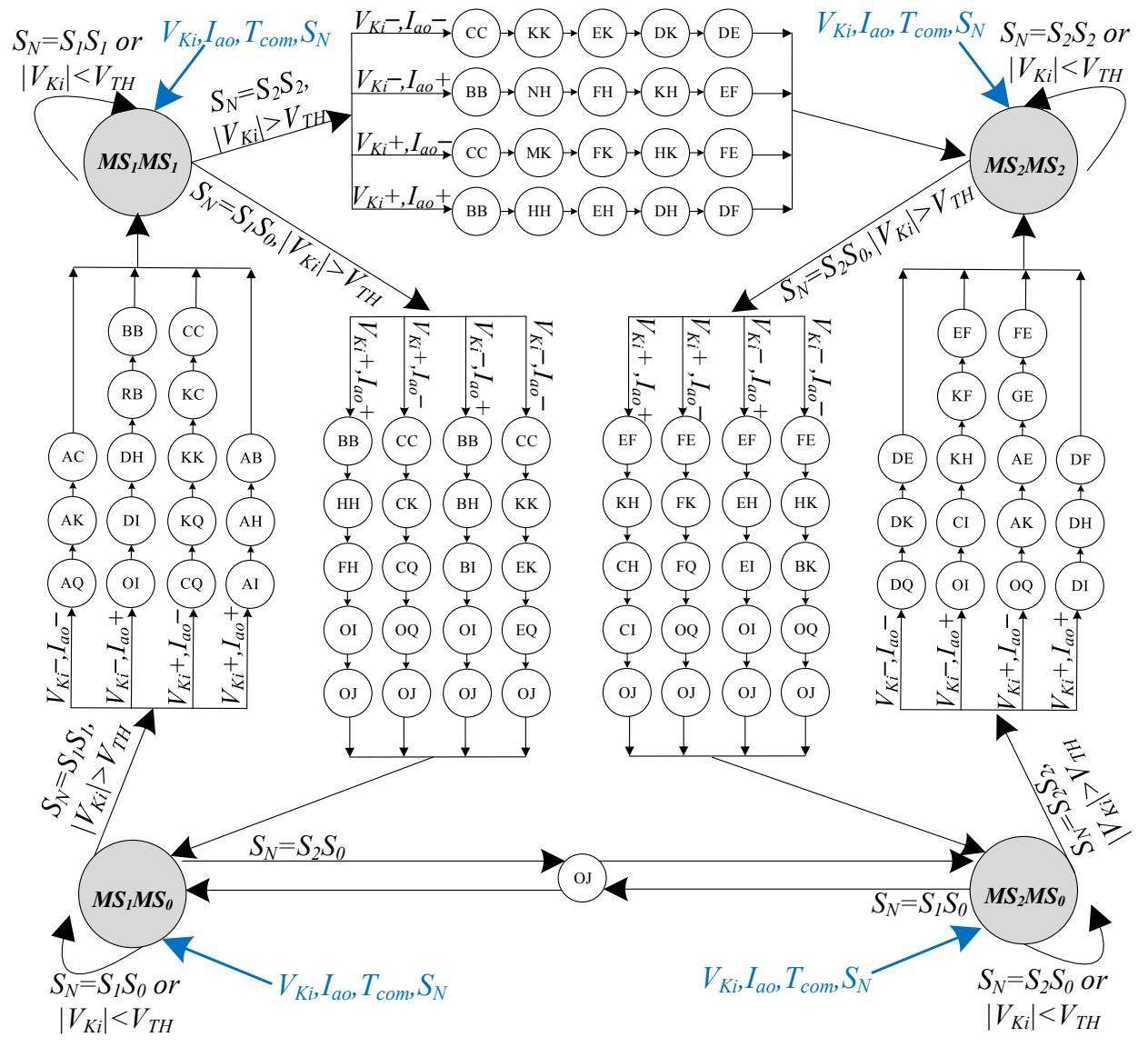

Fig. 8. Finite State Machine (FSM) for implementing the source-based commutation of on single-cell of the proposed MIMC 


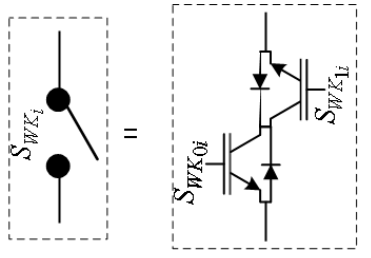

Fig. 9. Representation of an equivalent four-quadrant or bi-directional switch

then a counter will be started and will keep counting until it reaches the value equal that of $T_{\text {comm }}$ and once the counter has reached $T_{\text {comm }}$, FSM will move to next commutation state i.e. $H H$ which resets the counter to zero. For $V_{K i}$ and $I_{a o}$ represent the input voltages and output current, respectively. A detailed discussion on how the safe commutation is performed has already been presented in [35] and will not be discussed here. However, following the approach of [35], all the paths of FSM have been derived to guarantee safe commutation which can be verified from the results in the following sections.

$$
\begin{aligned}
& C S_{K i}=\left[\begin{array}{cc}
S_{W K_{0 i}} S_{W K_{1 i}} & S_{Y K_{0 i}} S_{Y K_{1 i}} \\
S_{Z K_{0 i}} S_{Z K_{1 i}} & S_{X K_{0 i}} S_{X K_{1 i}}
\end{array}\right], \\
& C S_{K o}=\left[\begin{array}{cc}
S_{W K_{0 o}} S_{W K_{1 o}} & S_{Y K_{0 o}} S_{Y K_{1 o}} \\
S_{Z K_{0 o}} S_{Z K_{1 o}} & S_{X K_{0 o}} S_{X K_{1 o}}
\end{array}\right] \\
& A=\left[\begin{array}{ll}
11 & 00 \\
00 & 11
\end{array}\right], B=\left[\begin{array}{ll}
10 & 00 \\
00 & 10
\end{array}\right], C=\left[\begin{array}{ll}
01 & 00 \\
00 & 01
\end{array}\right] \text {, } \\
& D=\left[\begin{array}{ll}
00 & 11 \\
11 & 00
\end{array}\right], E=\left[\begin{array}{ll}
00 & 10 \\
10 & 00
\end{array}\right], F=\left[\begin{array}{ll}
00 & 01 \\
01 & 00
\end{array}\right] \text {, } \\
& G=\left[\begin{array}{ll}
11 & 01 \\
01 & 11
\end{array}\right], H=\left[\begin{array}{ll}
10 & 01 \\
01 & 10
\end{array}\right], I=\left[\begin{array}{ll}
00 & 00 \\
01 & 10
\end{array}\right] \text {, } \\
& J=\left[\begin{array}{ll}
00 & 00 \\
11 & 11
\end{array}\right], K=\left[\begin{array}{ll}
01 & 10 \\
10 & 01
\end{array}\right], L=\left[\begin{array}{ll}
01 & 11 \\
11 & 01
\end{array}\right] \text {, } \\
& M=\left[\begin{array}{ll}
01 & 01 \\
01 & 01
\end{array}\right], N=\left[\begin{array}{ll}
10 & 10 \\
10 & 10
\end{array}\right], O=\left[\begin{array}{ll}
00 & 00 \\
00 & 00
\end{array}\right] \text {, } \\
& Q=\left[\begin{array}{ll}
00 & 00 \\
10 & 01
\end{array}\right], R=\left[\begin{array}{ll}
10 & 11 \\
11 & 10
\end{array}\right]
\end{aligned}
$$

\section{Simulation Results}

This section presents in Fig. 10 the results from a full three-phase to three-phase open-loop PLECS simulation of the MIMC. The simulation parameters are shown in Table I. The model includes the leakage-inductance-tolerant commutation scheme, whose effects on the THD of the output current in open loop has been evaluated as a function of the selected switching frequency, in the simplified assumption that the commutation time $T_{\text {comm }}$ is kept constant.

The MIMC operates with a fundamental frequency of $50 \mathrm{~Hz}$ at the input and $60 \mathrm{~Hz}$ at the output. This test case has been selected to show the applicability of the proposed system in applications requiring frequency decoupling e.g. 50 and $60 \mathrm{~Hz}$ grids or 50,25 and $16.7 \mathrm{~Hz}$ traction systems [10].

Fig. 10(a)-(b) present the three-phase input voltages $V_{K i}$ and the output currents $I_{j o}$ recorded in the three-phase to three-phase MIMC. By observing the period of the voltages
$V_{K i}$ and currents $I_{j o}$ in Fig. 10(a)-(b), three-phase operation of MIMC while achieving frequency adaptation can been confirmed. However, it must be noted from Fig. 10(b) that the output currents $I_{j o}$ are experiencing distortion which is associated with the leakage-inductance-tolerant commutation scheme. To illustrate the impact of commutation scheme, switching voltages and currents of a single-cell are presented in Fig. 10(c)-(e). By comparing the output voltage of cell $V_{B o}$, given in Fig. 10(e), with the ideal case, shown in Fig. 5(b), it can be noted that the red circles of Fig. 10(e) highlight the distortion added due to non-ideal commutation. To clearly illustrate the commutation-related distortion, a zoomed view of the highlighted-yellow-region in Fig. 10(c)-(e) is presented in Fig. 10(f)-(h) which shows two non-ideal state transitions, from $M S_{1} M S_{1}$ to $M S_{2} M S_{2}$ and then from $M S_{2} M S_{2}$ to $M S_{2} M S_{0}$.

Looking at the first commutation i.e. from $M S_{1} M S_{1}$ to $M S_{2} M S_{2}$ in Fig. 10(h), it can be observed that the output voltage $V_{B o}$ has commutation-associated distortion i.e. the pulse $V_{B o}=-V_{B i}$ which is highlighted in red region. By comparing non-ideal waveforms of Fig. 10(f)-(h) with the ideal waveforms given in Fig. 7(a)-(c), it can be confirmed that the distortion is associated with the commutation. The said distortion, highlighed in Fig. 10(h), happens when the leakage inductance $L_{l e a k}$ has been fully charged to $+I_{a o}$ and the converter is waiting for the next commutation state because a fixed commutation step $T_{\text {comm }}$ is used. Thus the duration of the distortion is dependent on the leakage inductance charging time which varies with the operating point i.e. depends on the magnitude of instantaneous values of input voltage $V_{K i}$ and output current $I_{a o}$. During the commutation process, the converter goes through various commutation states. For instance, the commutation under discussion takes the commutation states $C C, M K, F K, H K, F E$ of the FSM given in Fig. 8.

It is important to mention that the the output voltage distortion includes a low frequency component, a dominant component at the output frequency and multiples. For the sake of understanding the operation of the converter, only few $50 \mathrm{~Hz}$ cycles are adequate, as shown in the simulated results of Fig. 10(a)-(e), thus the period of $I_{T B}$ is not fully visible in

TABLE I

SIMULATION PARAMETERS

\begin{tabular}{c||c||c}
\hline Parameter & Symbol & Value \\
\hline \hline Input Frequency & $f_{i}$ & $50 \mathrm{~Hz}$ \\
Output Frequency & $f_{o}$ & $60 \mathrm{~Hz}$ \\
Input Voltage Amplitude & $V_{K i}$ & $200 \mathrm{~V}($ PEAK) \\
Load Resistance & $R$ & $10 \Omega$ \\
Load Inductance & $L$ & $10 \mathrm{mH}$ \\
Switching Frequency & $f_{\text {sw }}$ & $10 \mathrm{kHz}$ \\
Voltage Regulation Ratio & $q$ & 0.45 \\
Leakage Inductance & $L_{l e a k}$ & $2.5 \mu \mathrm{H}$ \\
\hline
\end{tabular}




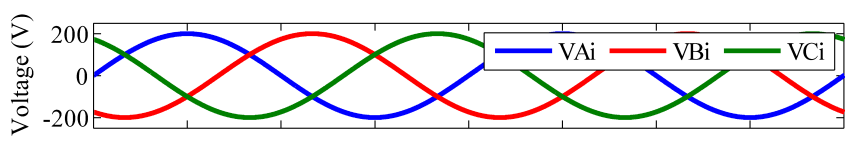

(a)

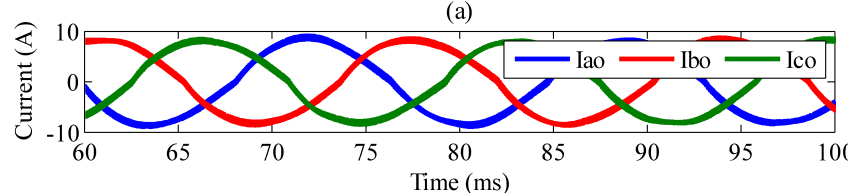

(b)

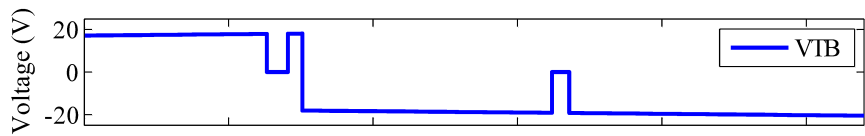

(f)

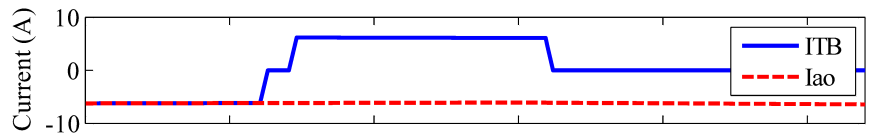

(g)

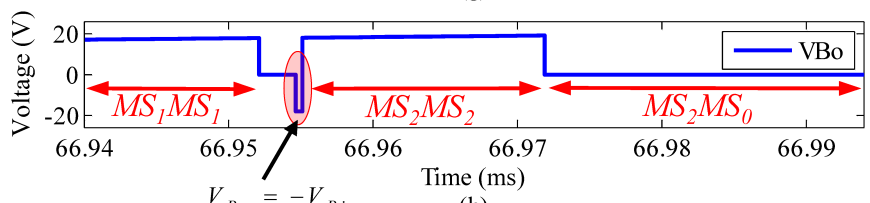

(h)

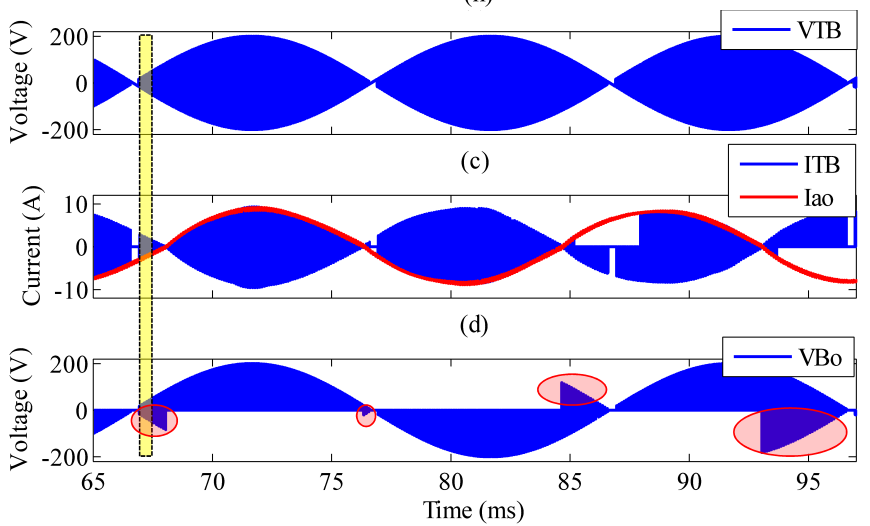

(e)

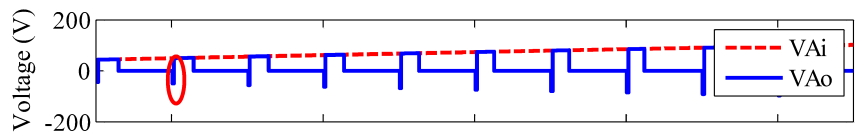

(i)

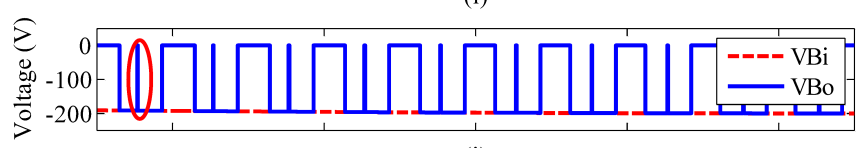

(j)

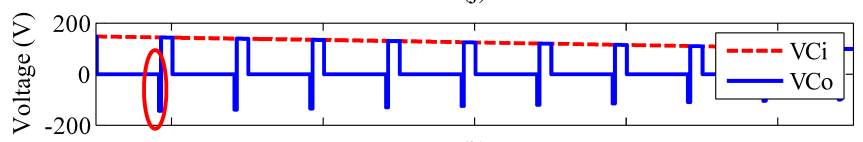

$(\mathrm{k})$

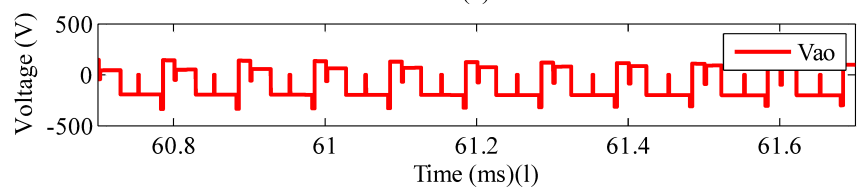

Fig. 10. Open Loop simulated waveforms at different points in the proposed three-phase to three-phase MIMC with Venturini Modulation and leakagetolerant commutation method. (a)-(b) Three phase input voltages $V_{K i}$ and output currents $I_{j o}$. (c)-(e) Waveforms in the second cell of Fig. 2. (f)-(h) Zoom on the highlighted region in (c)-(e), showing non-ideal commutations. (i)-(1) Cell output voltages $V_{K o}$ and total output voltage $V_{a o}$

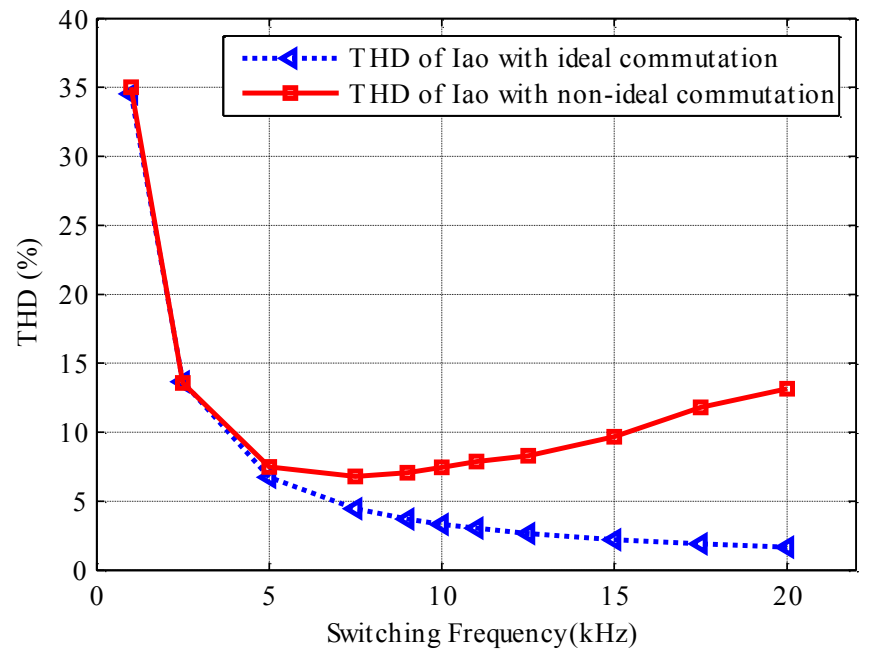

Fig. 11. Switching frequency vs. Total Harmonic Distortion (THD) with a fixed commutation time and filter inductor $L=10 \mathrm{mH}$ in the open-loop MIMC

Fig. 10(d).

To highlight how the switching output voltage $V_{a o}$ will look with the commutation method, cell voltage $V_{K o}$ waveforms are presented in Fig. 10(i)-(l). The detailed discussion on which commutation states are causing the distortion can be found in [35] and will not be discussed here.

In order to quantify the distortion associated with the commutation, the MIMC was operated with ideal as well as non-ideal commutation scheme and the THD of the output current $I_{a o}$ was observed at various switching frequencies as shown in Fig. 11. It can be observed from Fig. 11 that in ideal case, the THD of the output current $I_{a o}$ always has an inverse relation with the switching frequency $f_{s w}$ but this is not true for non-ideal case. Up till a switching frequency $f_{s w}$ of $5 \mathrm{kHz}$, the THD of both cases remain almost same as the fixed commutation time is negligible compared to the switching period but with the further increase of switching frequency $f_{s w}$, the fixed commutation time becomes significant part of the switching period therefore causing the THD to increase. The observed optimum range of operation for the MIMC is from 5 to $10 \mathrm{kHz}$. Within the optimum range, a higher switching frequency $f_{s w}$ will be preferred as the size of the magnetic components i.e. MF transformer will reduce. Therefore, a switching frequency $f_{s w}$ of $10 \mathrm{kHz}$ was selected in simulation as well as in the experimental setup.

\section{EXPERIMENTAL SETUP AND VALIDATION}

To validate the operation of the proposed MIMC topology, a $6 \mathrm{~kW}$ proof-of-concept laboratory scale prototype of the threephase to single-phase MIMC was built. The block diagram of experimental setup is shown in Fig. 12. A custom DSP/FPGA control platform, using a TMS320C6713DSK DSP and a ProASIC3 FPGA, has been used. Since there are 4 modulation states of each single-cell, as shown in Fig. 6, the DSP is implementing the switching functions of (7)-(9) by generating a total of 12 one-hot encoded modulation signals for three cells, i.e. 4 modulation signals per single-cell. The modulation signals 


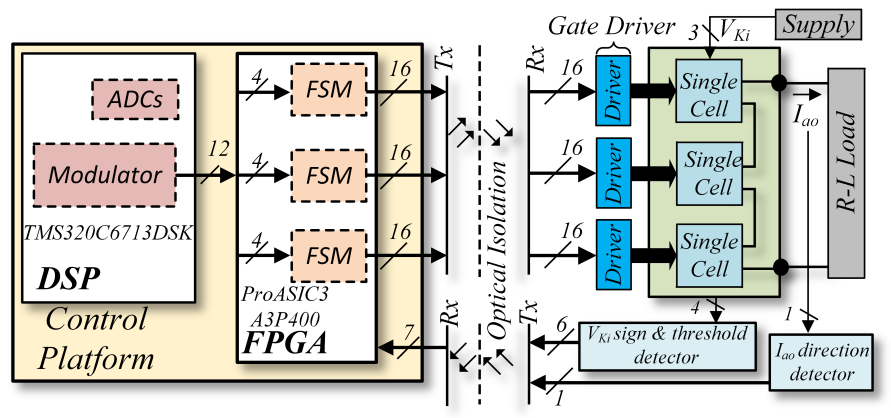

Fig. 12. Block diagram of the experimental setup for the three-phase to single-phase MIMC topology

are fed to the FPGA where a VHDL-based-FSM generates 16 independent gate signals per cell, based on the direction of output current $I_{a o}$, sign and threshold of input voltages $V_{K i}$, to perform the leakage-inductance-tolerant commutation. $V_{K i}$ sign and threshold detector block receives 4 electrical cables as the input voltage $V_{K i}$ is a three-phase four-wire system. The said block feeds 6 optical signals to the FPGA, out of which 3 contain the information of sign and the remaining 3 contains the information of the threshold. The threshold of the input voltages is detected to avoid commutation when the input voltage magnitude is below the set threshold. This can be observed in the simulation result of Fig. 10(d) where current $I_{T B}$ is zero i.e. no commutation is performed at the instants when magnitude of voltage $V_{T B}$ is close to zero. The value of threshold can be set by taking into account the peak value of current $I_{a o}$, leakage inductance $L_{\text {leak }}$, commutation time $T_{\text {comm }}$ and using simple formula $V_{T H}=\frac{\Delta I_{a \sigma} L_{\text {leak }}}{T_{\text {comm }}}$ where $\Delta I_{a o}=2 I_{a o}$ as leakage current changes between $I_{a o}$ and $-I_{a o}$. A total of 48 independent gate signals for three cells, generated by the FPGA, are then optically transmitted to the gate drivers of the SEMIKRON SKM150GM12T4G IGBT modules in the cells.

Fig. 13 shows the proof-of-concept experimental rig in which three single-cells are stacked. Each cell is made of two

TABLE II

TRANSFORMER PARAMETERS

\begin{tabular}{c|c}
\hline Parameter & Value \\
\hline \hline Core Material and shape & 2xAMCC125 C-cores \\
& Amorphous alloy 2605SA1 \\
Leakage Inductance & $4 \mu \mathrm{H}$ \\
Magnetizing Inductance & $2.3 \mathrm{mH}$ \\
Operating Frequency & $10 \mathrm{kHz}$ \\
Number of Turns & 16 \\
Turns Ratio & $1: 1$ \\
RMS current & $20 \mathrm{~A}$ \\
RMS voltage & $400 \mathrm{~V}$ \\
Power rating & $8 \mathrm{kVA}$ \\
\hline
\end{tabular}

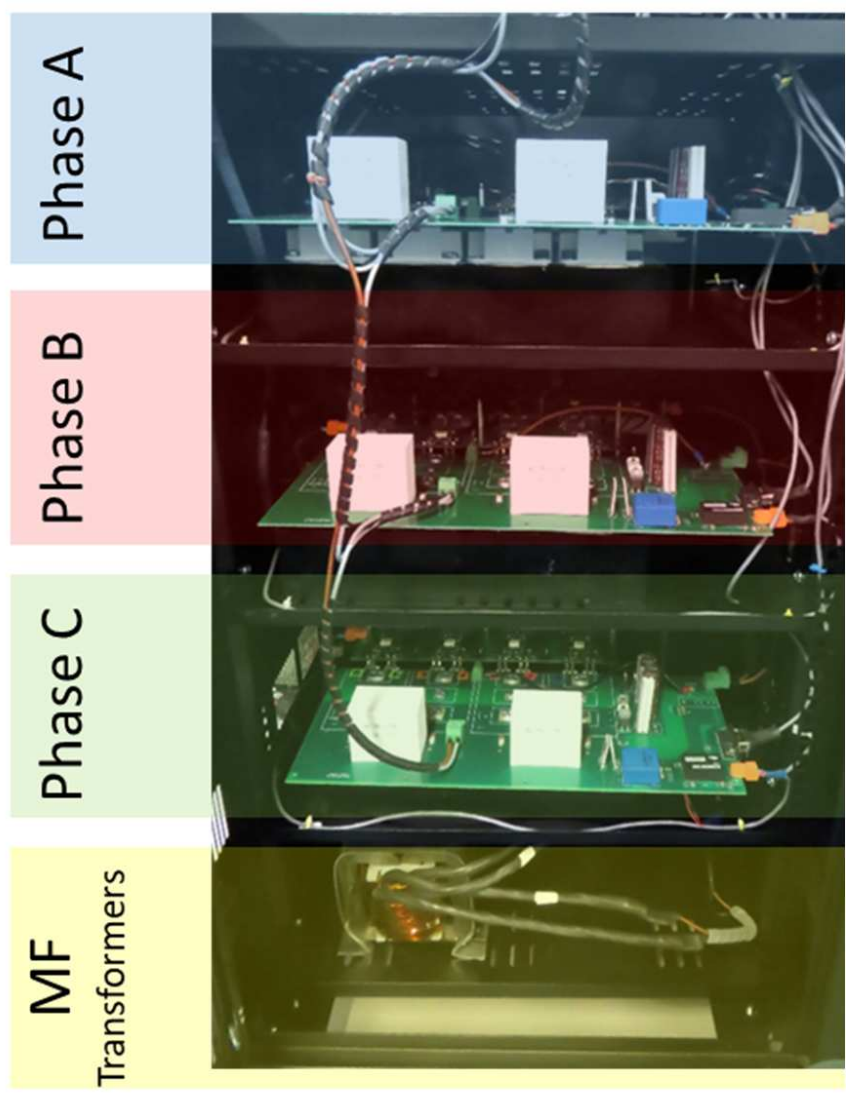

Fig. 13. Photo of the experimental proto-type for three-phase to single-phase MIMC topology based on Semikron SKM150GM12T4G modules

bidirectional bridges and a MF transformer. For the design of MF isolation transformer, the minimum core area $A_{c_{-} \text {min }}$ required, to accommodate the flux produced by the 50 duty cycle transformer voltage $V_{T K}$ of (12), can be calculated using (17) where $N$ represents the number of turns, $B_{\max }$ is the flux density of the core material, $V_{m}$ is the peak of the transformer voltage, $\omega_{s}$ represents switching frequency and $\omega_{i}$ is the input frequency. A MF transformer, with parameters reported in Table II, was designed to meet $A_{c}>A_{c_{-} \text {min }}$. However, the design has not been optimized for the topology under study as the experimental prototype is a flexible rig to test various topologies. It is important to mention that filter capacitors $C_{F}$, listed in III, are of Polypropylene Film type and are added to suppress the voltage spikes generated due to the switching current [40] through line inductance and to exhibit voltage source properties at the input side.

$$
A_{c_{-} \min }=\frac{4 V_{m} \omega_{s}}{N B_{\max } \pi} \sum_{n=1,3,5, \ldots}^{\infty} \frac{1}{n^{2} \omega_{s}^{2}+\omega_{i}^{2}}
$$

To validate the concept of the proposed topology, the experimental setup was first tested in open-loop mode to modulate a $60 \mathrm{~Hz}$ output from $50 \mathrm{~Hz}$ input. This test case has been considered to keep the results consistent with the ones in Section IV.

The setup was operated with the parameters reported in Table III and the recorded experimental waveforms are presented 
TABLE III

EXPERIMENTAL TEST PARAMETERS

\begin{tabular}{c||c||c}
\hline Parameter & Symbol & Value \\
\hline \hline Input Voltage Amplitude & $V_{K i}$ & $120 \mathrm{~V}(\mathrm{RMS})$ \\
Frequency at the input side & $f_{i}$ & $50 \mathrm{~Hz}$ \\
Frequency at the output side & $f_{o}$ & $60 \mathrm{~Hz}$ \\
Switching Frequency & $f_{s w}$ & $10 \mathrm{kHz}$ \\
Load Resistance & $R$ & $1.5 \Omega$ \\
Load Inductance & $L$ & $10 \mathrm{mH}$ \\
Input Filter Capacitance & $C_{F}$ & $30 \mu \mathrm{F}$ \\
\hline
\end{tabular}

in Fig. 14. From Fig. 14(a), it is important to note that the fundamental component of all the three-phase input voltages $V_{K i}$ is at $50 \mathrm{~Hz}$ whereas that of the filtered output current $I_{a o}$ is at $60 \mathrm{~Hz}$. Note that the current $I_{a o}$ is the average of the pulse-width-modulated output voltage $V_{a o}$. This confirms that the MIMC is able to achieve frequency decoupling by following equation (13) as the components except at $\omega_{o} t$ i.e. $\omega_{i} t+\phi_{K}$ and $2 \omega_{i} t \pm \omega_{o} t-\phi_{K}$ are cancelled due to the phase difference of $\frac{2 \pi}{3}$. Note that the experimental setup is only a three-phase to single-phase MIMC and hence the input side currents $I_{K i}$ are not sinusoidal, causing distortions in the input voltages $V_{K i}$ which will be mitigated in the full three-phase version.

Fig. 14(b) shows several cycles of the modulated output voltages of the individual cells $V_{K o}$ as well as the sum of these voltages which is the output voltage $V_{a o}$. At any time ' $t$ ' the output voltage $V_{a o}$ is the sum of the cell voltages $V_{K o}$ and follows (14) and this can be validated from Fig. 14(c) which is the zoomed view of the highlighted region of Fig. 14(b). A single switching period $T_{S}$ has been shown in Fig. 14(c) to clearly indicate that the duty cycles $D_{K a}$ are arranged in the pattern of $D_{A a}, D_{B a}, D_{C a}$ and are in accordance with the arrangement given in Fig. 4. Furthermore, note that the red regions in the results of Fig. 14(b) highlight the distortion added in the output voltages of cells $V_{A o}, V_{B o}, V_{C o}$ due to the commutation. These commutation related distortions in the proposed topology are analogous to the dead-time distortion in the standard two-level inverters, with the difference that the commutation in the MIMC is also generating low frequency components.

The zoomed view, presented in Fig. 14(c) confirms that the experimental waveforms of $V_{A o}, V_{B o}, V_{C o}$ and their sum $V_{a o}$ match with the simulated waveforms presented in Fig. 10(f)(i). Thus, the results of Fig. 14 have experimentally validated the open-loop operation of the proposed MIMC. However, to improve the quality of the output current $I_{a o}$, shown in Fig. 14(a), and to enhance the degree of controllability, a current-controller must be added.

\section{A. Current Control Design}

A Proportional-Resonant (PR) current-controller was implemented as it can offer sinusoidal current reference $I_{a o \_r e f}$

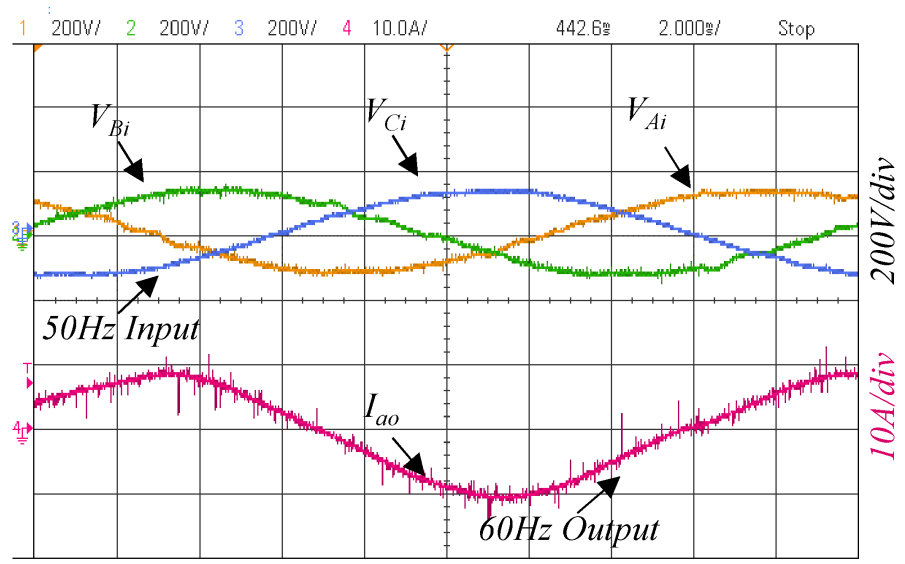

(a)

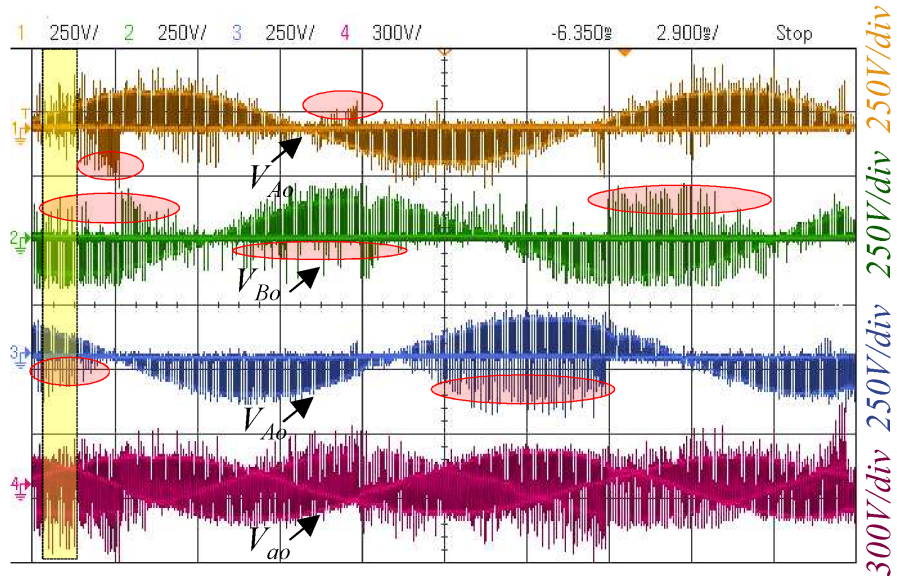

(b)

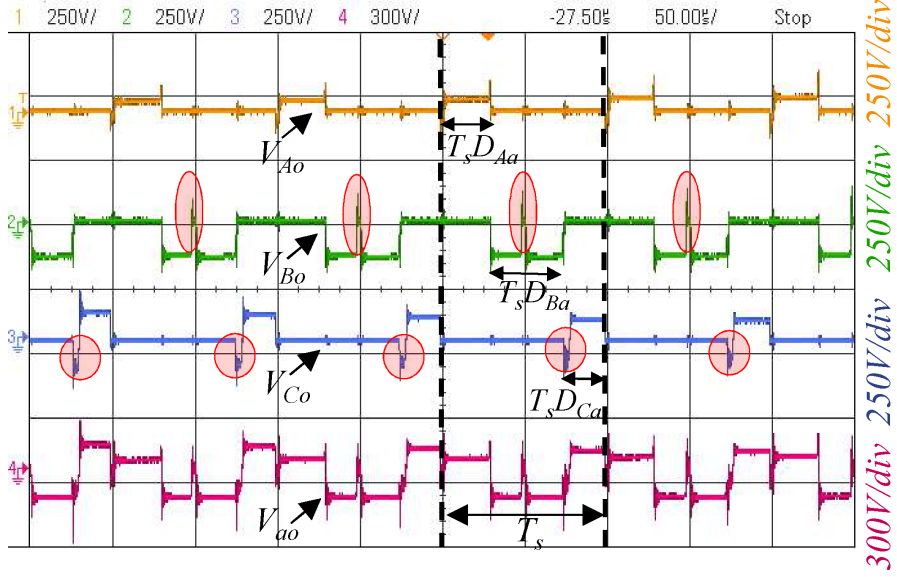

(c)

Fig. 14. Open-Loop experimental waveforms in a three-phase to single-phase MIMC. (a) Three-phase input voltages $V_{K i}$ at $50 \mathrm{~Hz}$ and output current $I_{a o}$ at $60 \mathrm{~Hz}$. (b) Individual cell voltages $V_{K o}$ and total output voltage $V_{a o}$. (c) Zoom of region highlighted in (b), demonstrating that the output voltage $V_{a o}$ is the sum of the individual cell voltages $V_{K o}$.

tracking. Moreover, thanks to the periodic-disturbance rejection capability [41], the commutation-related disturbances can be mitigated to enhance the quality of output current $I_{a o}$. The 


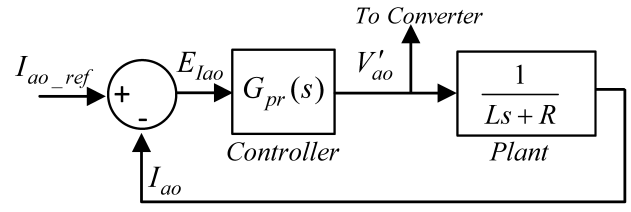

Fig. 15. Proportional-Resonant (PR) current-controller for MIMC

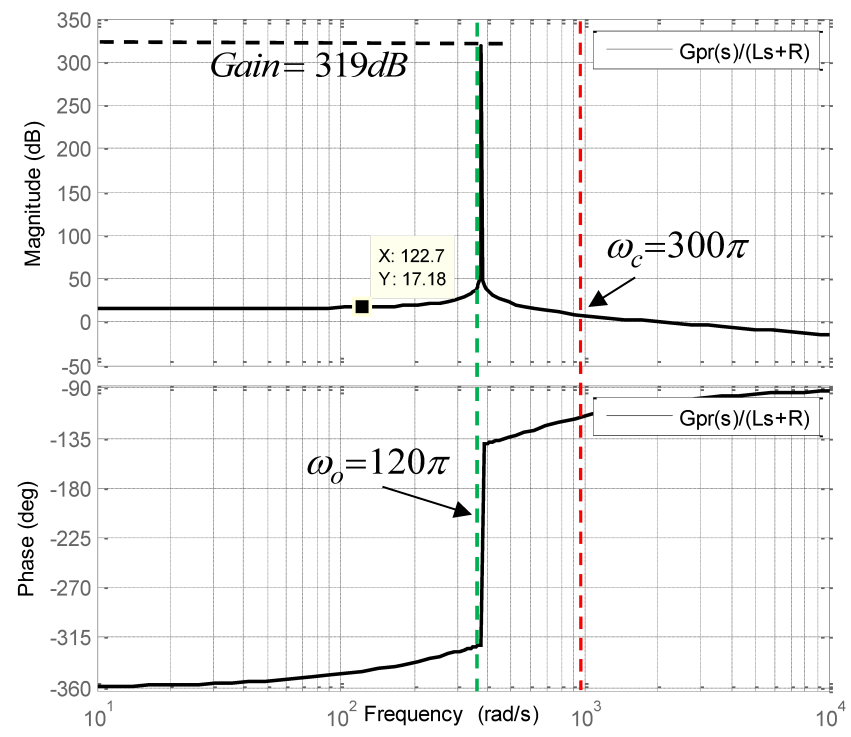

Fig. 16. Bode diagram of the current loop gain $\frac{G_{p r}(s)}{L s+R}$

transfer function of the PR controller [41] is given in (18) and the controller diagram is illustrated in Fig. 15 where $V_{a o}^{\prime}$ is the required output voltage to track the reference current $I_{a o_{-} r e f}$. The required output voltage $V_{a o}^{\prime}$ is fed to the MIMC's duty cycle equation (4). A Bode plot of the loop gain of the designed current controller is shown in Fig. 16.

$$
G_{p r}(s)=\frac{2 L \omega_{c} s^{2}+\left(L \omega_{c}^{2}+2 R \omega_{c}\right) s+R \omega_{c}^{2}}{s^{2}+\omega_{o}^{2}}
$$

A discretized version of the designed controller was implemented in the experimental rig and the recorded experimental waveforms of the output voltage $V_{a o}$ with and without controller are presented in Fig. 17(a). Looking closely at the waveforms of $V_{a o}$, it can be observed that the distortion is reduced in output voltage $V_{a o}$ when control loop is active but the improvement is not very clear because the output voltage $V_{a o}$ is a pulse-width modulated waveform. Therefore, for a clear comparison and to demonstrate the effectiveness of PR controller for MIMC, the output current in open-loop $I_{a o_{-} o p e n}$ is compared with the one in closed-loop $I_{a o_{-}}$closed in Fig. 17(b). As expected, Fig. 17(b) indicates that there is an enhancement in the quality of the output current $I_{a o_{c} \text { closed }}$ with the PR controller. To quantify this improvement, the FFTs of both currents $I_{a o_{-} o p e n}$ and $I_{a o_{c} c l o s e d}$ have been shown in Fig. 18. From Fig. 18, it can be seen that fundamental output frequency and the low-order harmonics which were present in the open-loop system, are compensated by the PR controller. Although maximum gain of PR controller is at

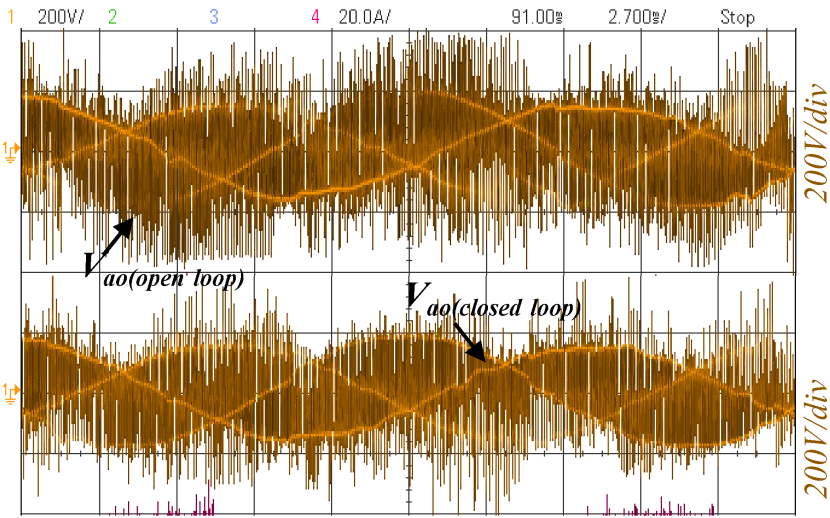

(a)

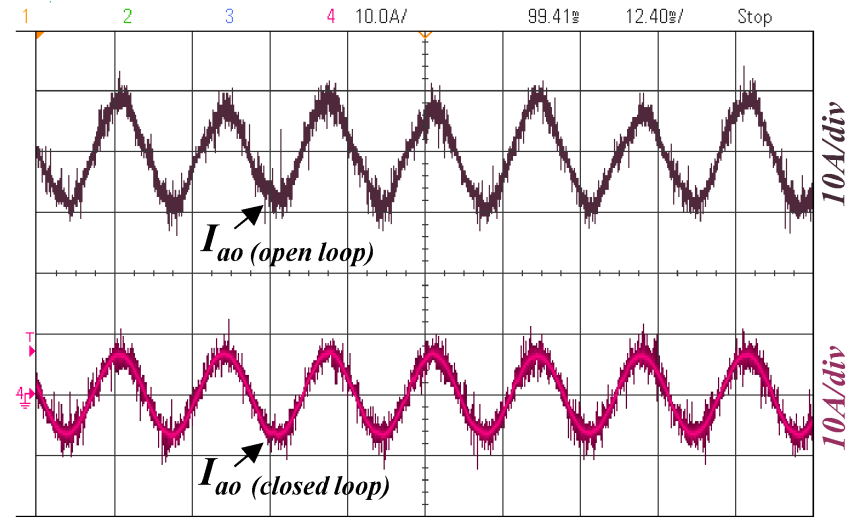

(b)

Fig. 17. Experimental waveforms at the output terminals of MIMC with and without closed-loop PR controller. (a) Output voltage $V_{a o}$ with and without controller (b) Output current $I_{a o}$ with and without controller

resonant frequency $\omega_{o}=120 \pi \mathrm{rad} / \mathrm{s}$ or $f_{o}=60 \mathrm{~Hz}$, the gain at low frequencies and at multiples of the fundamental is still non negligible and allows a partial compensation of the undesired components. A peak THD of $8.70 \%$ and an average THD of $5 \%$ were recorded in $I_{a o \text { open }}$ whereas a peak THD of $1.71 \%$ and an average THD of $1.52 \%$ were observed in $I_{a o_{-}}$closed .

Note that a single PR controller was implemented as the main scope of the paper is validation of the MIMC's operation. However, to achieve higher control performances, a more sophisticated controller can be used to enhance the compensation capabilities at higher frequencies.

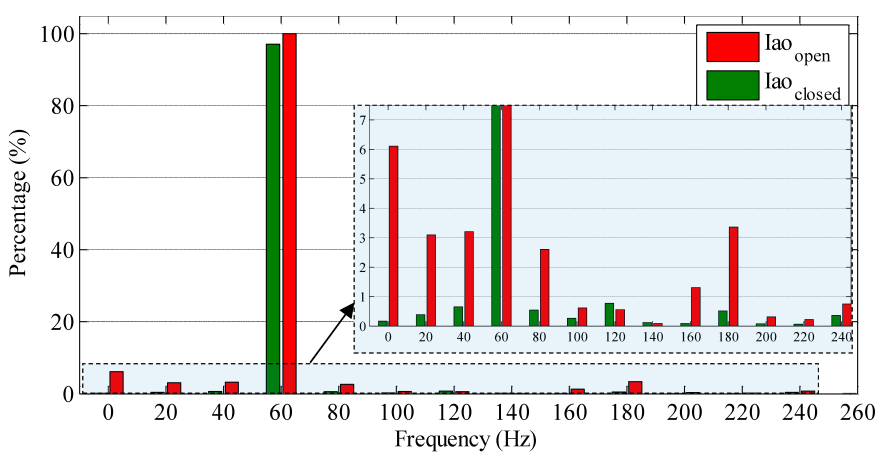

Fig. 18. FFT spectrums of output current $I_{a o}$ in open and closed loop systems with fixed output filter inductance i.e. $L=10 \mathrm{mH}$ 
Furthermore, the response of the closed-loop system as a result of step change in current reference $I_{a o_{-} r e f \_p k}$ from $3 \mathrm{~A}$ to $2 \mathrm{~A}$, was observed and recorded. The experimental waveforms are presented in Fig. 19(b). It can be noted from Fig. 19(b) that the system is stable and tracks the reference current $I_{a o_{-} r e f}$. Matching simulation results are presented in Fig. 19(a)-(c). A zoomed view of highlighted region of Fig. 19(a)-(b), presented in Fig. 19(c)-(d), shows the transient response of controller in simulation and experiment. Fig. 19(d) has some additional distortions near the zero-crossing of the current i.e at $\mathrm{t}=-5 \mathrm{~ms}$ and $\mathrm{t}=3 \mathrm{~ms}$ which is due to the sign of the current $I_{a o}$ being detected incorrectly when the magnitude is too small, causing the selection of wrong commutation path in the FSM of Fig. 8. This is due to the limitations of the sign detection hardware (shown in Fig. 12). However, the controller is taking necessary action to compensate these distortions. The reason why the same distortions are not present in the simulation result of Fig. 19(c) is that an ideal sign block is used in the simulation model.

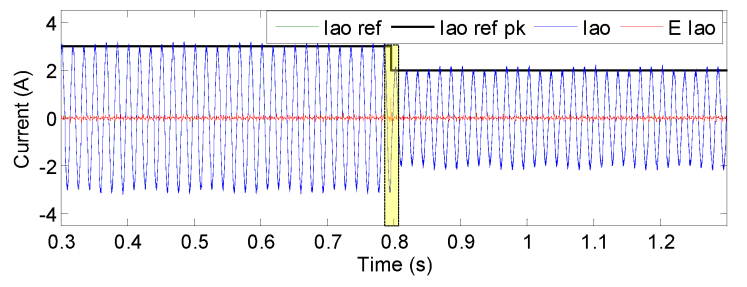

(a) Step change - Simulation

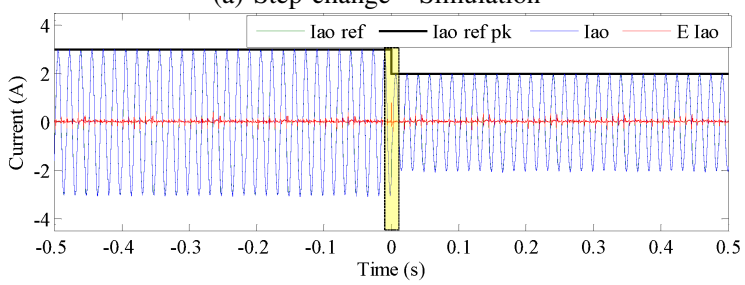

(b) Step change - Experiment

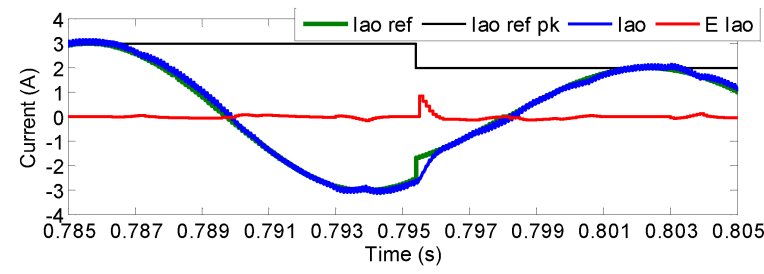

(c) Transient - Simulation

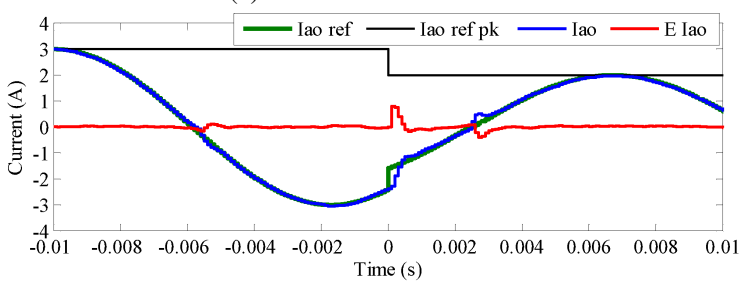

(d) Transient - Experiment

Fig. 19. Response of the closed-loop PR current-controller in a three-phase to single-phase MIMC topology. (a)-(b) A step-change in output current reference $I_{\text {ao ref }}$ from $3 \mathrm{~A}$ to $2 \mathrm{~A}$. (c)-(d) Zoom of region highlighted in (a)(b), showing the error $E_{I a o}$ compensation during transient due to step-change in $I_{a o_{-} r e f \_p k}$

\section{CONCLUSION}

This paper has presented a comprehensive study on modulation, commutation and control methods for a Modular Isolated Matrix Converter (MIMC) topology. The experimental results have validated the conceptual MIMC topology, demonstrating its practical feasibility. The design and implementation of the modulation for the MIMC topology is derived from a generalisation of standard modulation methods used in matrix converters. Instead, commutation between states is particularly challenging because of the leakage inductance of the MF transformer that provides isolation to the topology. However, the paper demonstrated that the implementation of a leakageinductance-tolerant commutation enables a safe operation of the converter also in a practical scenario. The proposed MIMC topology can find its $\mathrm{AC} / \mathrm{AC}$ applications where weight and volume are the main priority i.e. in traction applications and grid applications with space restrictions.

\section{APPENDIX \\ DERIVATION OF TRANSFORMER VOLTAGE $V_{T K}$ AND CELL VOLTAGE $V_{K o}$}

The transformer voltage of the first cell i.e. $V_{T A}(t)$ is function of input voltage $V_{A i}$ and 50\% duty-cycle square wave $s(t)$ therefore, can be expressed as (21) which can be simplified to (23). The generalised form of transformer voltage $V_{T K}$, given in (12), can be obtained by similar approach.

$$
\begin{gathered}
V_{A i}(t)=V_{m} \sin \left(\omega_{i} t\right) \\
s(t)=\frac{4}{\pi} \sum_{n=1,3,5, \ldots}^{\infty}\left[\frac{1}{n} \sin \left(n \omega_{s} t\right)\right] \\
V_{T A}(t)=V_{A i}(t) s(t) \\
V_{T A}(t)=\frac{4 V_{m}}{\pi} \sum_{n=1,3,5, \ldots}^{\infty}\left[\frac{1}{n} \sin \left(\omega_{i} t\right) \sin \left(n \omega_{s} t\right)\right] \\
V_{T A}(t)=\frac{2 V_{m}}{\pi} \sum_{n=1,3,5, \ldots}^{\infty} \frac{1}{n} \\
{\left[\cos \left(n \omega_{s} t-\omega_{i} t\right)-\cos \left(n \omega_{s} t+\omega_{i} t\right)\right]}
\end{gathered}
$$

The output voltage of the first cell i.e. $V_{A o}(t)$ is function of duty cycle $D_{A a}$ and input voltage $V_{A i}$, therefore, can be expressed as (25). Substitution of (19) and (24) to (25), yields (26) which is simplified to form (28) after trigonometric manipulation. Following the same approach, a generalised expression of (13) representing all cell output voltages $V_{K o}$ is determined.

$$
\begin{gathered}
D_{A a}(t)=\frac{1}{3}\left(1+2 q \sin \left(\omega_{i} t\right) \sin \left(\omega_{o} t\right)\right) \\
V_{A o}(t)=V_{A i}(t) D_{A a}(t) \\
V_{A o}(t)=\frac{V_{m}}{3} \sin \left(\omega_{i} t\right)\left[1+2 q \sin \left(\omega_{i} t\right) \sin \left(\omega_{o} t\right)\right] \\
V_{A o}(t)=\frac{V_{m}}{3} \sin \left(\omega_{i} t\right)+\frac{q V_{m}}{3} \sin \left(\omega_{o} t\right)\left[1-\cos \left(2 \omega_{i} t\right)\right]
\end{gathered}
$$




$$
\begin{array}{r}
V_{A o}(t)=\frac{V_{m}}{3} \sin \left(\omega_{i} t\right)+\frac{q V_{m}}{6} \sin \left(2 \omega_{i} t-\omega_{o} t\right)- \\
\frac{q V_{m}}{6} \sin \left(2 \omega_{i} t+\omega_{o} t\right)+\frac{q V_{m}}{3} \sin \left(\omega_{o} t\right)
\end{array}
$$

\section{REFERENCES}

[1] A. Alesina and M. G. B. Venturini, "Analysis and design of optimumamplitude nine-switch direct ac-ac converters," IEEE Transactions on Power Electronics, vol. 4, no. 1, pp. 101-112, 1989.

[2] P. W. Wheeler, J. Rodriguez, J. C. Clare, L. Empringham, and A. Weinstein, "Matrix converters: a technology review," Industrial Electronics, IEEE Transactions on, vol. 49, no. 2, pp. 276-288, 2002.

[3] T. Friedli, J. W. Kolar, J. Rodriguez, and P. W. Wheeler, "Comparative evaluation of three-phase ac-ac matrix converter and voltage dc-link back-to-back converter systems," IEEE Transactions on Industrial Electronics, vol. 59, no. 12, pp. 4487-4510, 2012.

[4] M. Galea, G. Buticchi, L. Empringham, L. d. Lillo, and C. Gerada, "Design of a high-force-density tubular motor," IEEE Transactions on Industry Applications, vol. 50, no. 4, pp. 2523-2532, 2014.

[5] S. Bifaretti, P. Zanchetta, A. Watson, L. Tarisciotti, and J. C. Clare, "Advanced power electronic conversion and control system for universal and flexible power management," IEEE Transactions on Smart Grid, vol. 2, no. 2, pp. 231-243, 2011.

[6] S. F. Pinto, P. Alcaria, J. Monteiro, and J. F. Silva, "Matrix converterbased active distribution transformer," IEEE Transactions on Power Delivery, vol. 31, no. 4, pp. 1493-1501, 2016.

[7] J. E. Huber and J. W. Kolar, "Solid-state transformers: On the origins and evolution of key concepts," IEEE Industrial Electronics Magazine, vol. 10 , no. 3, pp. 19-28, 2016.

[8] J. E. Huber and J. Kolar, "Applicability of solid-state transformers in today's and future distribution grids," IEEE Transactions on Smart Grid, pp. 1-1, 2018.

[9] D. Dujic, F. Kieferndorf, F. Canales, and U. Drofenik, "Power electronic traction transformer technology," in Proceedings of The 7th International Power Electronics and Motion Control Conference, vol. 1, Conference Proceedings, pp. 636-642.

[10] P. Drabek, Z. Peroutka, M. Pittermann, and M. Cedl, "New configuration of traction converter with medium-frequency transformer using matrix converters," IEEE Transactions on Industrial Electronics, vol. 58, no. 11, pp. 5041-5048, 2011

[11] A. Q. Huang, "Medium-voltage solid-state transformer: Technology for a smarter and resilient grid," IEEE Industrial Electronics Magazine, vol. 10, no. 3, pp. 29-42, 2016.

[12] H. Chen and D. Divan, "Design of a 10 kva soft-switching solid state transformer (s4t)," IEEE Transactions on Power Electronics, vol. PP, no. 99 , pp. $1-1,2017$.

[13] p. 24, 1968.

[14] S. Falcones, R. Ayyanar, and X. Mao, "A dc-dc multiport-converterbased solid-state transformer integrating distributed generation and storage," IEEE Transactions on Power Electronics, vol. 28, no. 5, pp. 2192 2203, 2013.

[15] S. Xu, A. Q. Huang, and R. Burgos, "Review of solid-state transformer technologies and their application in power distribution systems," IEEE Journal of Emerging and Selected Topics in Power Electronics, vol. 1, no. 3, pp. 186-198, 2013.

[16] H. S. Krishnamoorthy, P. Enjeti, and J. J. Sandoval, "Solid state transformer for grid interface of high power multi-pulse rectifiers," IEEE Transactions on Industry Applications, pp. 1-1, 2017.

[17] Y. Liu, Y. Liu, H. Abu-Rub, B. Ge, R. S. Balog, and Y. Xue, "Model predictive control of a matrix-converter based solid state transformer for utility grid interaction," in 2016 IEEE Energy Conversion Congress and Exposition (ECCE), Conference Proceedings, pp. 1-6.

[18] J. J. Sandoval, S. Essakiappan, and P. Enjeti, "A bidirectional series resonant matrix converter topology for electric vehicle dc fast charging," in 2015 IEEE Applied Power Electronics Conference and Exposition (APEC), Conference Proceedings, pp. 3109-3116.

[19] A. Rufer, N. Schibli, C. Chabert, and C. Zimmermann, "Configurable front-end converters for multicurrent locomotives operated on $162 / 3$ $\mathrm{hz}$ ac and $3 \mathrm{kv}$ dc systems," Power Electronics, IEEE Transactions on, vol. 18, no. 5, pp. 1186-1193, 2003.

[20] H. Chen, A. Prasai, R. Moghe, K. Chintakrinda, and D. Divan, "A 50 kva three-phase solid state transformer based on the minimal topology: Dyna-c," IEEE Transactions on Power Electronics, pp. 1-1, 2016.

[21] H. Qin and J. W. Kimball, "Solid-state transformer architecture using ac-ac dual-active-bridge converter," IEEE Transactions on Industrial Electronics, vol. 60, no. 9, pp. 3720-3730, 2013.
[22] H. Chen and D. Divan, "Soft-switching solid-state transformer (s4t)," IEEE Transactions on Power Electronics, vol. 33, no. 4, pp. 2933-2947, 2018.

[23] K. Basu, A. Shahani, A. K. Sahoo, and N. Mohan, "A single-stage solidstate transformer for pwm ac drive with source-based commutation of leakage energy," IEEE Transactions on Power Electronics, vol. 30, no. 3, pp. 1734-1746, 2015

[24] K. Basu and N. Mohan, "A single-stage power electronic transformer for a three-phase pwm ac/ac drive with source-based commutation of leakage energy and common-mode voltage suppression," IEEE Transactions on Industrial Electronics, vol. 61, no. 11, pp. 5881-5893, 2014.

[25] D. Boroyevich, I. Cvetković, D. Dong, R. Burgos, F. Wang, and F. Lee, "Future electronic power distribution systems a contemplative view," in 2010 12th International Conference on Optimization of Electrical and Electronic Equipment, Conference Proceedings, pp. 1369-1380.

[26] R. Silversides, T. Green, and M. M. C. Merlin, "A high density converter for mid feeder voltage regulation of low voltage distribution feeders," in 2014 IEEE Energy Conversion Congress and Exposition (ECCE), Conference Proceedings, pp. 1972-1978.

[27] Y. Sun, W. Xiong, M. Su, H. Dan, X. Li, and J. Yang, "Modulation strategies based on mathematical construction method for multimodular matrix converter," IEEE Transactions on Power Electronics, vol. 31, no. 8, pp. 5423-5434, Aug 2016.

[28] U. Nasir, M. Rivera, A. Costabeber, and P. Wheeler, "A venturini based modulation technique for a new isolated ac/ac power converter," in IECON 2016 - 42nd Annual Conference of the IEEE Industrial Electronics Society, Conference Proceedings, pp. 6243-6248.

[29] M. Kang, P. N. Enjeti, and I. J. Pitel, "Analysis and design of electronic transformers for electric power distribution system," Power Electronics, IEEE Transactions on, vol. 14, no. 6, pp. 1133-1141, 1999.

[30] C. Daolian and L. Lei, "Bi-polarity phase-shifted controlled voltage mode ac/ac converters with high frequency ac link," in Power Electronics Specialist Conference, 2003. PESC '03. 2003 IEEE 34th Annual, Conference Proceedings, pp. 677-682.

[31] C. Daolian and L. Jian, "The uni-polarity phase-shifted controlled voltage mode ac-ac converters with high frequency ac link," Power Electronics, IEEE Transactions on, vol. 21, no. 4, pp. 899-905, 2006.

[32] L. Lei and Z. Qinglong, "Comparisons of two kinds of ac/ac converters with high frequency link," in IECON 2008. 34th Annual Conference of the IEEE Industrial Electronics Society, Conference Proceedings, pp. $618-622$.

[33] N. Burany, "Safe control of four-quadrant switches," in Industry Applications Society Annual Meeting, 1989., Conference Record of the 1989 IEEE, Conference Proceedings, pp. 1190-1194 vol.1.

[34] B. Wang and E. Sherif, "Spectral analysis of matrix converters based on 3-d fourier integral," IEEE Transactions on Power Electronics, vol. 28, no. 1, pp. 19-25, 2013.

[35] U. Nasir, A. Costabeber, M. Rivera, P. Wheeler, and J. Clare, "A leakageinductance-tolerant commutation strategy for isolated ac/ac converters," IEEE Journal of Emerging and Selected Topics in Power Electronics, pp. 1-1, 2018.

[36] D. Chen and Y. Chen, "Step-up ac voltage regulators with highfrequency link," IEEE Transactions on Power Electronics, vol. 28, no. 1, pp. 390-397, 2013.

[37] H. Krishnaswami and V. Ramanarayanan, "Control of high-frequency ac link electronic transformer," IEE Proceedings - Electric Power Applications, vol. 152, no. 3, pp. 509-516, 2005.

[38] H. Keyhani, H. A. Toliyat, M. Harfman-Todorovic, R. Lai, and R. Datta, "An isolated resonant ac-link three-phase ac-ac converter using a single hf transformer," IEEE Transactions on Industrial Electronics, vol. 61, no. 10 , pp. 5174-5183, 2014.

[39] F. H. Khan, L. M. Tolbert, and W. E. Webb, "Hybrid electric vehicle power management solutions based on isolated and nonisolated configurations of multilevel modular capacitor-clamped converter," Industrial Electronics, IEEE Transactions on, vol. 56, no. 8, pp. 3079-3095, 2009.

[40] K. Yamada, T. Higuchi, E. Yamamoto, H. Hara, T. Sawa, M. M. Swamy, and T. Kume, "Integrated filters and their combined effects in matrix converter," in Fourtieth IAS Annual Meeting. Conference Record of the 2005 Industry Applications Conference, 2005., vol. 2, Oct 2005, pp. 1406-1413 Vol. 2.

[41] A. Kuperman, "Proportional-resonant current controllers design based on desired transient performance," IEEE Transactions on Power Electronics, vol. 30, no. 10, pp. 5341-5345, 2015. 


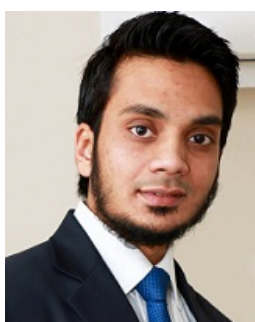

Usman Nasir (S'13) received the B.Sc. degree in electrical engineering from the National University of Sciences and Technology, Islamabad, Pakistan, in 2013, and the M.Sc. degree in electric power system and its automation from North China Electric Power University, Beijing, China, in 2015. He is currently pursuing the Ph.D. degree in electrical engineering with the Power Electronics and Machine Control Research Group, University of Nottingham, Nottingham, U.K. His current research interests include new matrix converter-based topologies, novel commutation algorithms, new modulation techniques, model predictive control for converters and high-power density SiC converters. Mr. Nasir is a recipient of the Dean of Engineering Scholarship for International Research Excellence for his Ph.D. studies. He received the best paper award from the IEEE Southern Power Electronics Conference 2017, Chile.

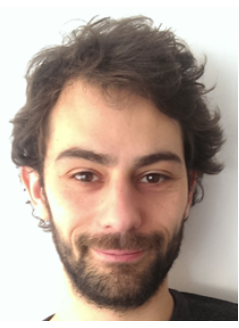

Alessandro Costabeber (S'09-M'13) received the M.Sc. degree (Hons.) in electronic engineering and the $\mathrm{Ph} . \mathrm{D}$. degree in information engineering from the University of Padova, Padua, Italy, in 2008 and 2012, respectively. His Ph.D. thesis was on energyefficient architectures and control for future residential microgrids. In 2014, he joined as a Lecturer in power electronics with the Power Electronics and Machine Control Research Group, University of Nottingham, Nottingham, U.K. His current research interests include modular multilevel converters for HVDC, high-power density converters, and control and stability analysis of ac and dc microgrids. Dr. Costabeber received the IEEE Joseph John Suozzi INTELEC Fellowship Award in Power Electronics in 2011.

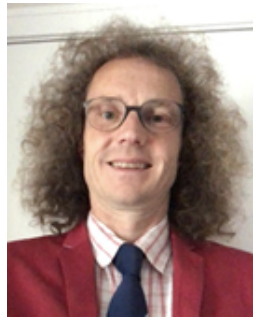

Patrick Wheeler (M'01-SM'10) received his BEng (Hons.) degree in 1990 from the University of Bristol, UK. He received his $\mathrm{PhD}$ degree in Electrical Engineering for his work on Matrix Converters from the University of Bristol, UK in 1994. In 1993 he moved to the University of Nottingham and worked as a research assistant in the Department of Electrical and Electronic Engineering. In 1996 he became a Lecturer in the Power Electronics, Machines and Control Group at the University of Nottingham, UK. Since January 2008 he has been a Full Professor in the same research group. He was Head of the Department of Electrical and Electronic Engineering at the University of Nottingham from 2015 to 2018. $\mathrm{He}$ is currently the Head of the Power Electronics, Machines and Control Research Group, Global Director of the University of Nottingham's Institute of Aerospace Technology and is the Li Dak Sum Chair Professor in Electrical and Aerospace Engineering. He is a member of the IEEE PELs AdCom and was an IEEE PELs Distinguished Lecturer from 2013 to 2017. He has published 500 academic publications in leading international conferences and journals.

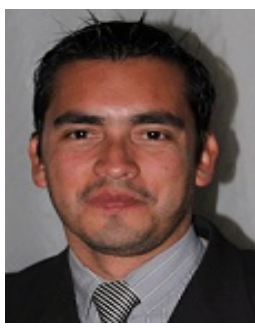

Marco Rivera (S'09-M'11) received the B.Sc. degree in electronics engineering and the M.Sc. degree in electrical engineering from the Universidad de Concepción, Concepción, Chile, in 2007 and 2008, respectively, and the Ph.D. degree from the Department of Electronics Engineering, Universidad Técnica Federico Santa María, Valparaíso, Chile, in 2011. He is currently a Professor with the Department of Electrical Engineering, Universidad de Talca, Curicó, Chile. His current research interests include matrix converters, predictive and digital controls for high-power drives, four-leg converters, and the development of highperformance control platforms based on field-programmable gate arrays Dr. Rivera received the Premio Tesis de Doctorado Academia Chilena de Ciencias 2012 in 2013 for his best Ph.D. thesis developed in 2011 for national and foreign students in any exact or natural sciences program that is a member of the Academia Chilena de Ciencias, Chile. In 2015, he received the Oustanding Engineer of 2015 Award from the Chilean Association of Electrical and Electronics Industry and the IEEE-Chile. He received a scholarship from the Chilean Research Fund CONICYT for his Ph.D. studies.

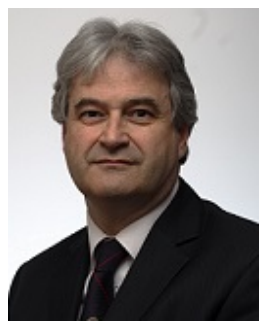

Jon Clare (M'90-SM'04) was born in Bristol, U.K., in 1957. He received the B.Sc. and Ph.D. degrees in electrical engineering from the University of Bristol, Bristol, U.K., in 1979 and 1983, respectively. From 1984 to 1990, he was a Research Assistant and Lecturer with the University of Bristol, where he was involved in teaching and research on power electronic systems. Since 1990, he has been with the Power Electronics, Machines and Control Group, University of Nottingham, Nottingham, U.K., where he is currently a Professor of Power Electronics and head of electronic and electrical engineering department. His research interests include power-electronic converters and modulation strategies, variable-speeddrive systems, and electromagnetic compatibility 